\title{
ANTONIO DE ARFE Y JUAN BAUTISTA CELMA. DOS MODOS DE INTERPRETAR, DESDE EL ARTE, EL PAISAJE ${ }^{1}$
}

\author{
José Manuel García Iglesias \\ Universidade de Santiago de Compostela
}

\begin{abstract}
RESUMEN
La valoración, desde la percepción del paisaje que conllevan, tanto de la custodia como de los púlpitos de la Catedral de Santiago de Compostela nos pone en relación con dos momentos diferentes en la vida del leonés Antonio de Arfe -1542 , fecha aproximada de la concreción del basamento del primer piso de dicha custodia, y 1573, fecha a relacionar tanto con la peana y el sagrario en el que se asienta- $y$, también, otros dos del aragonés Juan Bautista Celma -1578, fecha en que asume la realización de los púlpitos, y 1583/1586, que es cuando los concluye-. Los criterios desde los que trabaja Antonio de Arfe el paisaje y la forma en que, por una parte, los continúa Juan Bautista Celma y, por otra, los reformula, es el objeto de este estudio.
\end{abstract}

Palabras clave: Antonio de Arfe, Juan Bautista Celma, custodia, púlpito, paisaje

\section{ABSTRACT}

An appraisal of both the monstrance and the pulpits of the Cathedral of Santiago de Compostela, from within the landscape of which they form part, provides us with a link to two different points in the life of Antonio de Arfe of Leon. These are 1542, the approximate date of the completion of the base of the lower section of the monstrance, and 1573, a date linked to the pedestal and the sacrarium on which it is seated. There also exists a connection with two phases in the life of Juan Bautista Celma of Aragon: namely 1578, the year in which he took on the task of creating the pulpits, and 1583-1586, the period in which he completed them. This study focuses on the criteria De Arfe used in working on the landscape and the manner in which Celma both continues with and reformulates them.

Keywords: Antonio de Arfe, Juan Bautista Celma, monstrance, pulpit, landscape

1. Las obras de la custodia procesional, el sagrario y los púlpitos de la Catedral de Santiago

Antonio de Arfe (León, ca. 1510- Madrid, ca. 1575) ${ }^{2}$, un orfebre, y Juan Bautista Celma (Aragón, ca. 1535- Santiago de Compostela, 1608) ${ }^{3}$, un polifacético pintor, son los autores a relacionar con dos de las obras gallegas del siglo XVI en las que la interpretación del paisaje cuenta con una presencia muy significativa, a las que dedicamos este trabajo ${ }^{4}$.

En primer lugar la custodia de asiento ${ }^{5}$ de la Catedral de Santiago de Compostela se do- cumenta como obra de Antonio de Arfe $^{6}$, en la que cabe valorar diferentes momentos de obra (Fig. 1). Existe un primer tiempo, entre 1539 y 1543, en el que concretó el cuerpo de la custodia. Más tarde, entre 1571 y 1573, se realizará su basamento; cuenta éste con las marcas de Valladolid, del marcador Gonzalo Escobar, y del propio Arfe. También, en 1573, como obra complementaria de la custodia, se le añade , a modo de peana, un sagrario -que reemplaza a otro anterior-; todo ello se dispone en el centro del altar mayor al menos desde 1569 pero, quizás ya, en un tiempo ligeramente anterior ${ }^{7}$. Ambrosio de Morales, en 1572, también alude a 


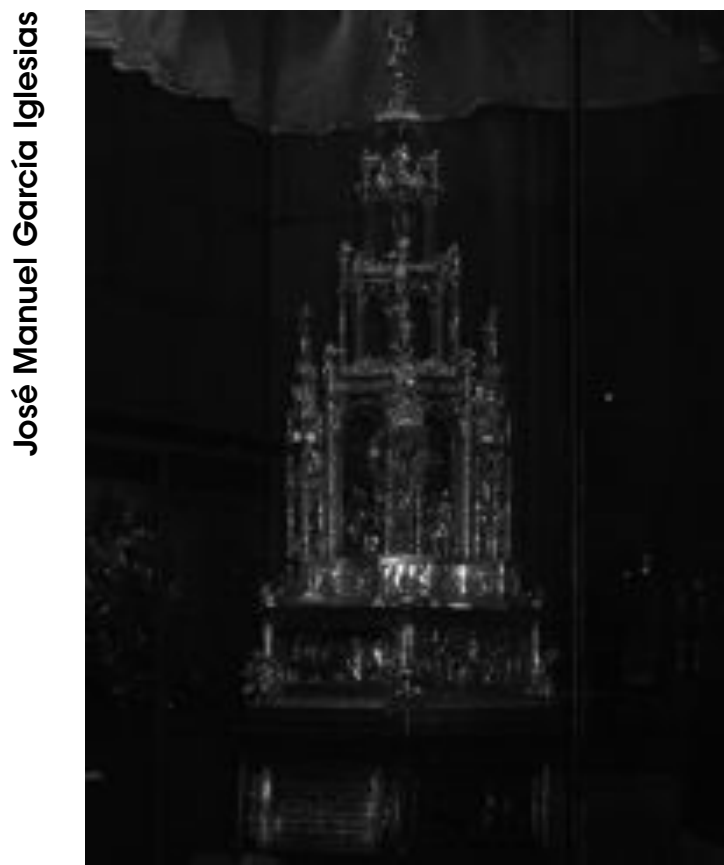

Fig. 1. Custodia de asiento de la Catedral de Santiago de Compostela

esta ubicación de la custodia, con independencia de que, además, se utiliza en las procesiones $^{8}$. Se encontrará allí, todavía, según Recuento de $1658^{\circ}$. Después la reforma barroca llevará a esta custodia y sagrario a otro lugar.

Pues bien, en lo que concierne a la presencia, en este conjunto -custodia y sagrario-, del paisaje, cabe decir que si el basamento primero de la custodia cuenta con treinta y seis temas, doce de ellos nos presentan a otros tantos profetas que se nos muestran en hornacinas cubiertas con venera, en tanto que, en las restantes, se presenta toda una historia de la vida de Jesús que se inicia con el tema de la Anunciación y se concluye con una Anástasis. Pues bien, once de las veinticuatro escenas aquí recogidas cuentan con notaciones paisajísticas, de mayor o menor entidad. El autor intercala, a la hora de desarrollar el relato, dos tipos de espacios. Uno es rectangular de carácter apaisado y de mayor tamaño; así se nos muestra lo siguiente: Adoración de los pastores, Entrada en Jerusalén, Prendimiento, Jesús con la cruz a cuestas, Jesús clavado en la cruz. El otro, también rectangular, y de condición menor, se dispone verticalmente; en los marcos correspondientes se ubican las siguientes escenas con paisaje: Huida a Egipto, Bautismo, Oración en el Huerto, Cristo con San Pedro, Deposición, Anástasis.

El basamento, fruto, como se ha dicho, de un momento considerablemente posterior, presenta, en tanto, seis escenas: La elección de Santiago y Juan, hijos del Zebedeo; Transfiguración; La condena y martirio de Santiago; Traslación; Milagros de Duio y Negreira; y "Del peregrino colgado a quien el Santo Apóstol salvó de la muerte..." (Milagro del Apóstol en Santo Domingo de la Calzada). El sagrario, en tanto, repite alguno de estos temas en su perímetro.

Juan Bautista Celma es, por otra parte, el "pintor aragonés" que, en torno a 158310, trabaja en una obra que terminará por 1586"11: los púlpitos del Evangelio y de la Epístola, con sus respectivos corredores, de la Catedral de Santiago, labor, por cierto, prevista ya muchos años puesto que el Cabildo llama a Celma, por entonces en Oviedo, en 1564, para encomendarle las trazas correspondientes. No será, sin embargo, hasta 1578 el momento en que la obra parece iniciarse ${ }^{12}$. Tal como he señalado, en otro lugar $^{13}$, el plan iconográfico que cabe valorar en los púlpitos y sus corredores, pueden verse las siguientes escenas en el púlpito del Evangelio: Traslación del cuerpo de Santiago, El cuerpo del Apóstol llega a Padrón, Milagros de Duio y Negreira, "Del peregrino colgado a quien el santo Apóstol salvó de la muerte...", y la Elección de Santiago y Juan, hijos del Zebedeo. En tanto, en el púlpito del lado de la Epístola se disponen: El Tributo de las cien doncellas, Convocatoria y audiencia de la Corte, la Aparición al rey don Ramiro, la Batalla de Clavijo y la Defensa de Santiago (habitualmente denominada como la Derrota de los normandos). En lo relativo a los corredores, se ubica en el lado del Evangelio, la Condena y martirio de Santiago; y en el de la Epístola, a Alfonso II, ante la tumba apostólica.

Dos cuestiones previas a tener en cuenta, desde la perspectiva en la que aquí nos interesa incidir: Por una parte, el púlpito y el corredor del lado del evangelio -en un caso con una mínima alteración en el dibujo- se repiten escenas ya hechas para el basamento de la custodia, de- 
jando de reproducirse, en este caso, el tema de la Transfiguración, y duplicando, en el púlpito, con un sustancial matiz, la escena de la Traslación. Tal reiteración, con respecto a la obra de la custodia, ha llevado a proponer que lo que hace Celma, en este caso, es reproducir unos modelos previos, relacionados, de una u otra forma, con Antonio de Arfe. En segundo término -y en lo que concierne ya más directamente a la cuestión paisajística- cabe resaltar el hecho de que diez de las doce escenas de este ciclo conllevan estudios paisajísticos ya que, tan solo, dos temas - Convocatoria y audiencia de la Corte y Alfonso II ante la tumba apostólica- carecen de este recurso temático.

\section{3)}

\section{La primera obra de la custodia (1539-}

Las cinco escenas dispuestas en los marcos apaisados -Adoración de los pastores, Entrada en Jerusalén, Prendimiento, Jesús con la cruz a cuestas, Jesús clavado en la cruz- aportan similares características (Figs. 2, 3 y 4). Siempre lo fundamental del relato se dispone en el primer plano, atendiendo, en el reparto compositivo de las figuras, a criterios de equidad espacial y orden, propios de un pensamiento renacentista. Por lo que se refiere a la cuestión paisajística ha de entenderse aquí siempre como un fondo imaginado, con notaciones arquitectónicas y algunas alusiones al relieve, siempre concebidas en función de lo que el primer plano aporta y, entendiéndolo, en todo caso, como un modo de buscar el equilibrio compositivo, a nivel general. La línea del horizonte se concibe, sin embargo, atendiendo a criterios diversos; así en la Adoración de los Pastores y El Prendimiento se dispone sumamente elevada, en tanto que, en los temas que nos muestran a Jesús con la cruz a cuestas y clavado en la cruz se ubica hacia la media del relieve; por lo demás, en la Entrada en Jerusalén el relato parece recortarse, sobre un cielo, dejando lo paisajístico relegado a un extremo.

Las seis historias, ubicadas en los marcos verticales -Huida a Egipto, Bautismo, Oración en el Huerto, Cristo con San Pedro, Deposición,

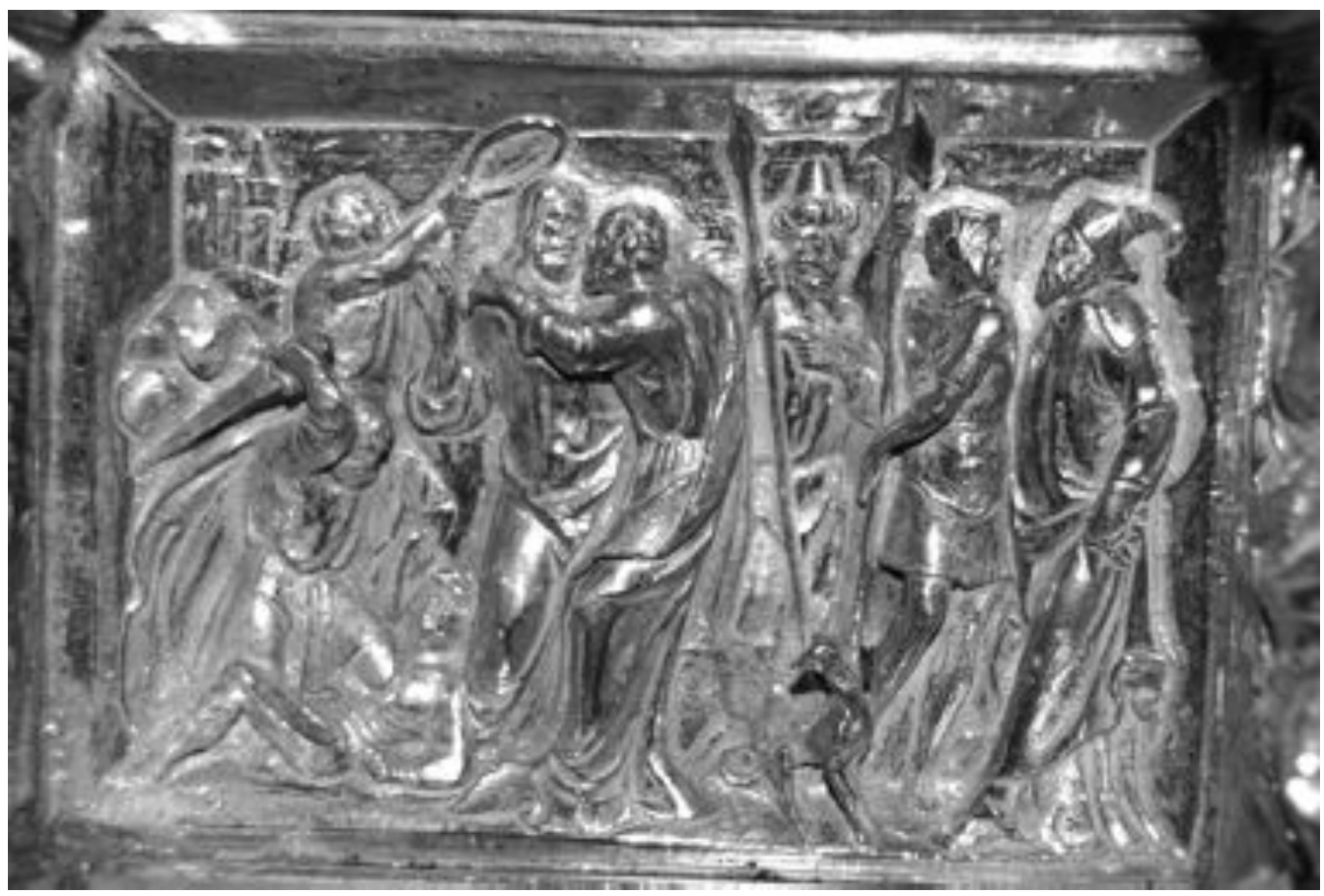

Fig. 2. Prendimiento 


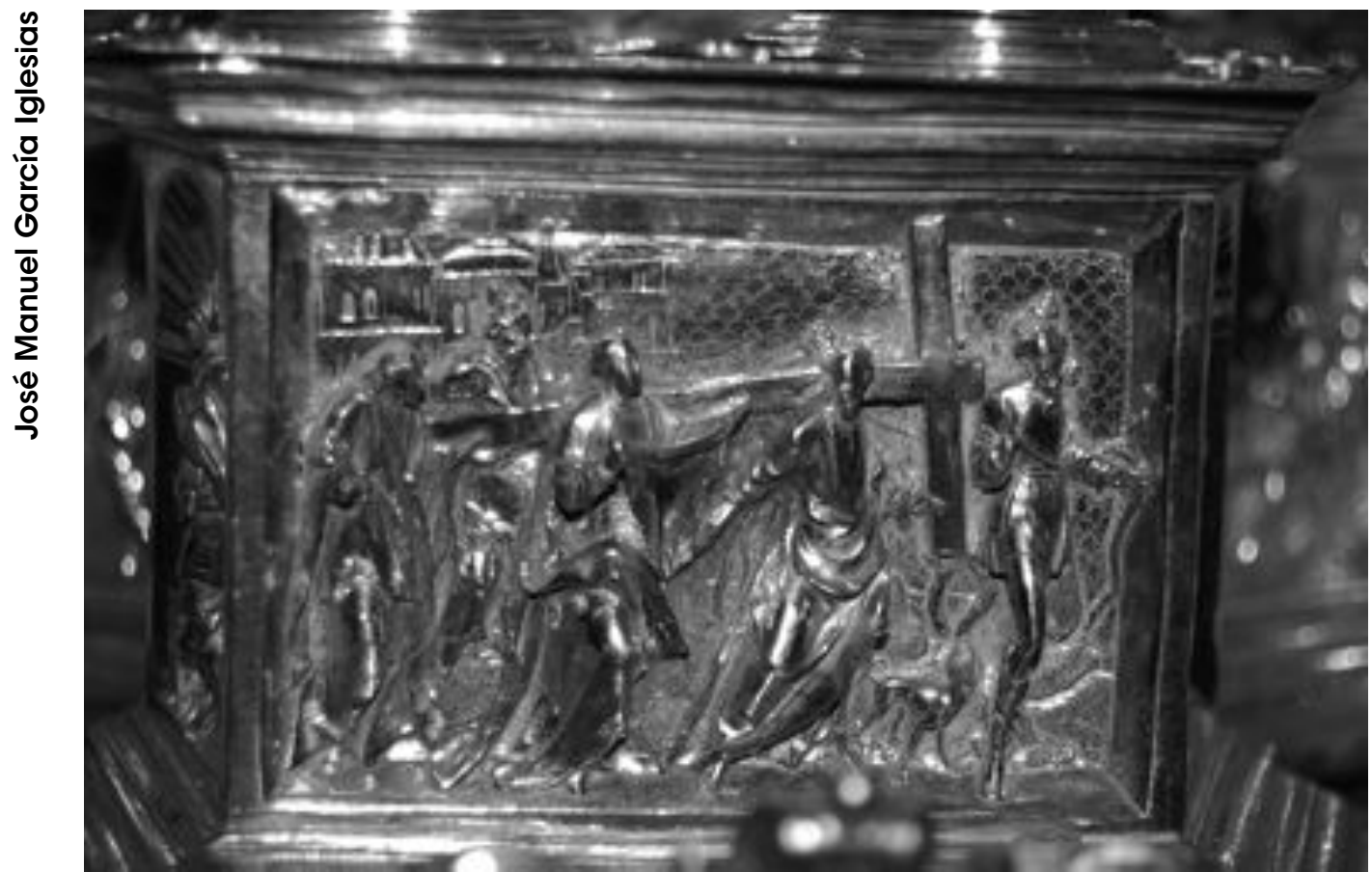

Fig. 3. Jesús con la cruz a cuestas

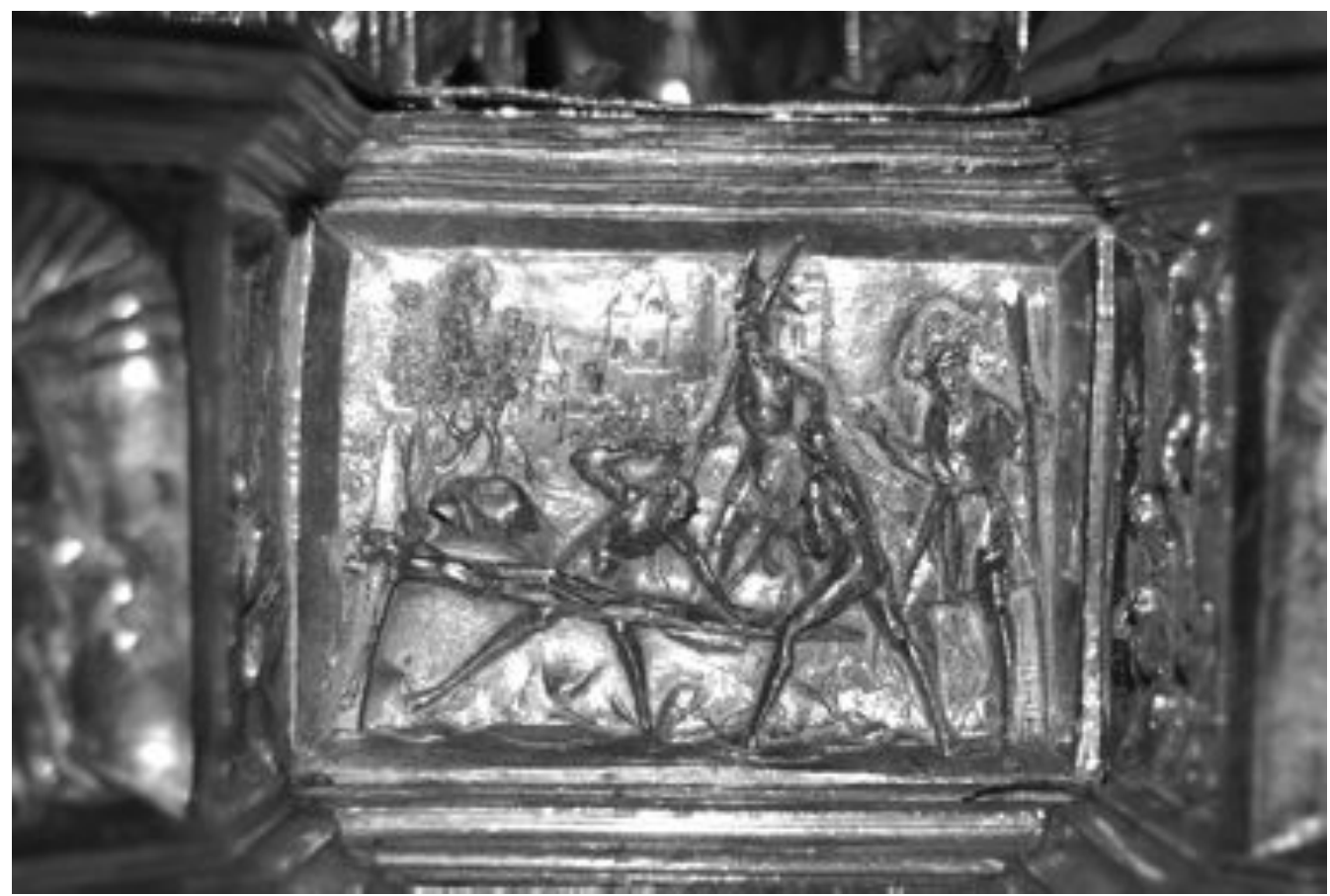

Fig. 4. Jesús clavado en la cruz 
Anástasis-, han de adaptar su interpretación del paisaje, en general a la generación de dos registros superpuestos en altura. De este modo, el relato se dispone en la parte inferior y se deja lo demás, según los casos, a la naturaleza, tierra y cielo, y, en un caso -Cristo con San Pedro-, también, a arquitecturas que ambientan la representación y, a su modo, la enriquecen. Sin embargo, en dos asuntos, la Huida a Egipto y el Bautismo, el tratamiento de lo paisajístico se reduce a mostrarnos, en un lateral, en el primer caso una palmera, y en el segundo un árbol ${ }^{14}$. De este modo las figuras que forman parte de la composición se recortan sobre el cielo, dándose, así, una sensación del espacio abierto en el que discurre la acción.

En todo caso, las escenas en cuestión se encuadran en la utilización de fórmulas muy simples en la aplicación de criterios renacentistas. La pequeñez del espacio en que se incluyen -con respecto a lo que se pretende narrar- propicia el carácter un tanto sintético, desde el que se conciben.

\section{La base, añadida, a la custodia (1571- 1573)}

En las seis escenas que el basamento presenta cabe distinguir, por una parte, el modo de entender el paisaje en la escena de la Transfiguración $y$, por otra, en las demás historias narradas. Se trata, en todos los casos, de temas dispuestos en espacios rectangulares de condición apaisada.

Y es que la escena de la Transfiguración es la única de las aquí existentes que guarda una cierta proximidad, en su modo de concebirse, con respecto a la obra realizada por Antonio de Arfe unos treinta años antes (Fig. 5). De hecho podría decirse que, en un tamaño considerablemente mayor, utiliza similares criterios. Se divide aquí el espacio en tres partes: una central, de mayor tamaño, en la que se contempla al Padre, delimitado por una mandorla, diciendo desde lo alto: "Este es mi Hijo, el amado, en quien tuve mi complacencia, escuchadle". Se muestran a sus lados, sobre las nubes, a Moisés y a Elías, y abajo, postrados, a tres apóstoles: Pedro, Santiago, en el centro, y Juan. Dos árboles, encuadran

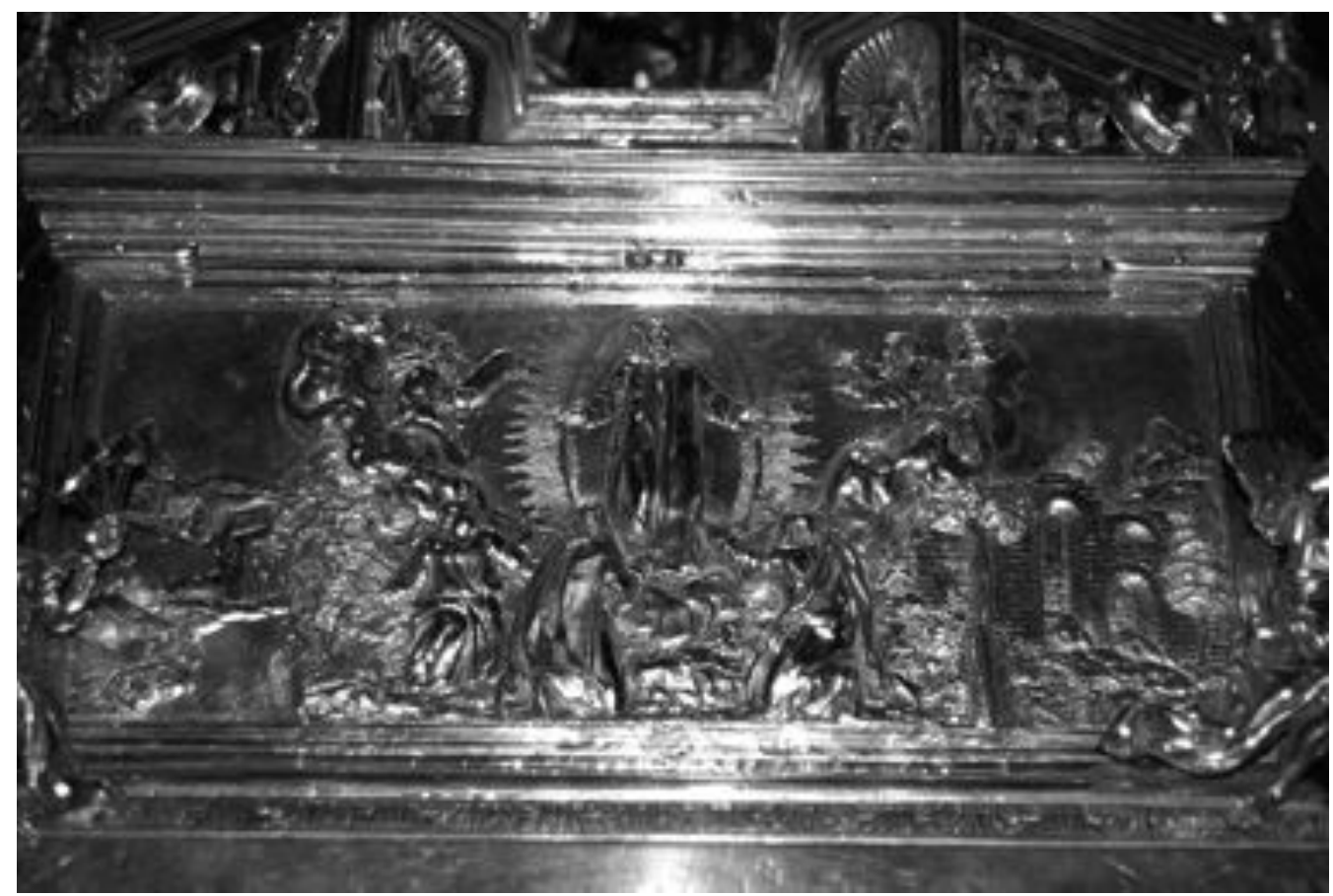

Fig. 5. La Transfiguración 


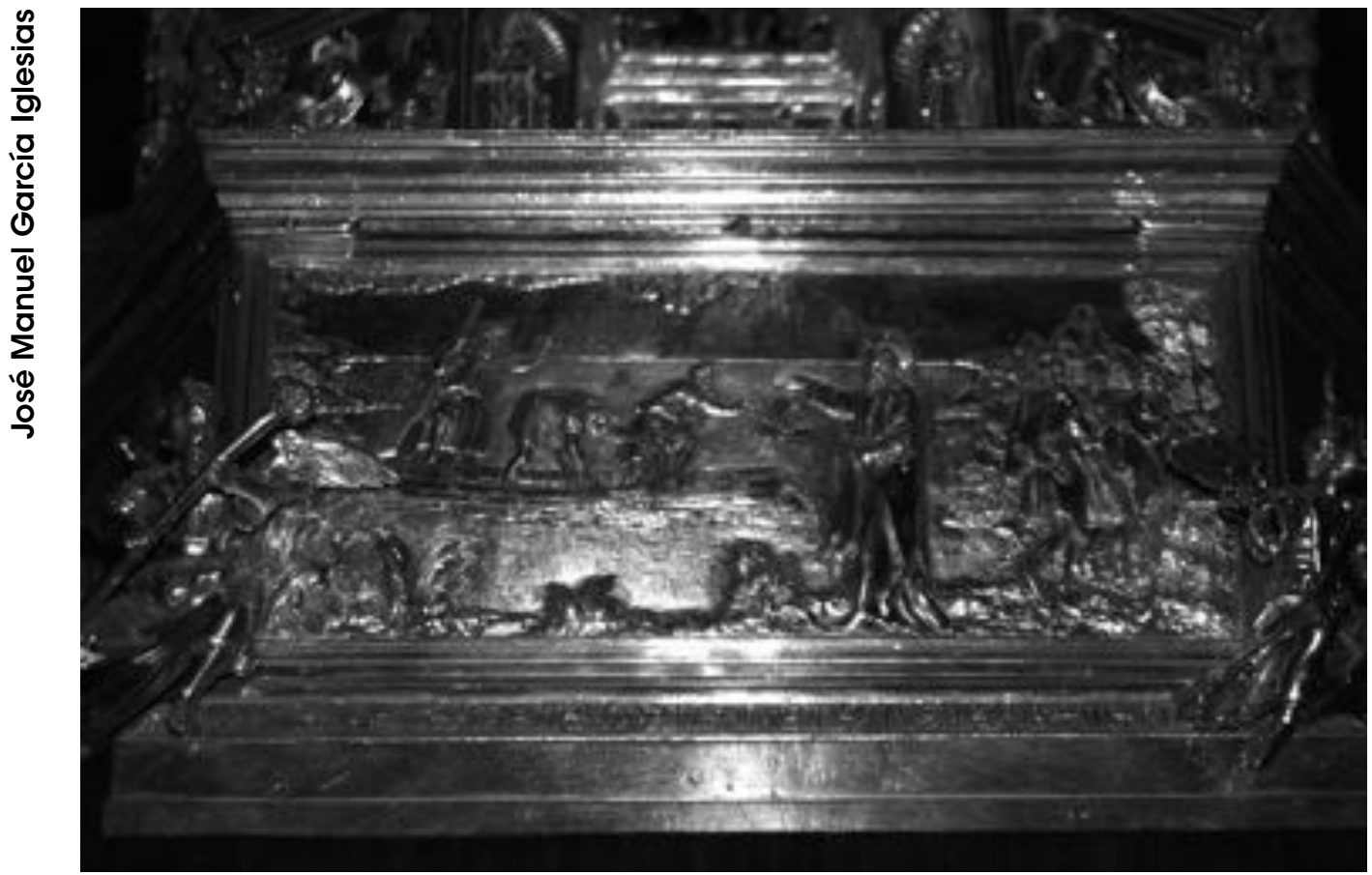

Fig. 6. La elección de Santiago y Juan

esta zona media del relieve, algo que, si por una parte, refuerza el sentido de la simetría ${ }^{15}$, también puede ponerse en relación con el modo en que se nos muestra, al propio Santiago, en el relato de este mismo episodio, en la portada de Platerías ${ }^{16}$. En tanto el autor de esta composición presenta, a cada lado un retazo de paisaje en el que se esboza la presencia de algunas construcciones que colaboran a generar una cierta sensación de profundidad. En este caso la línea del horizonte se dispone, aproximadamente, a una altura media dentro de la composición.

Las otras cinco escenas atienden, en cambio, a criterios compositivos, y de concepción del paisaje, claramente diferentes, respondiendo, todos ellos, a muy parecidas formulaciones. La Elección de Santiago y Juan, hijos del Zebedeo, nos muestra a Jesús, en su llamada a los hijos del Zebedeo, con quien comparte el trabajo en una barca que faena, próxima a la orilla, en el mar de Galilea -o lago de Genesaret, según el relato de Lucas $^{17}$ (Fig. 6). Cristo está en un primer plano, en pie, dirigiéndose a ellos, en un espacio ambientado con una pareja de aves y algún arbusto que contribuyen a resaltar ese primer término, de condición terrestre. La línea del horizonte se dispone muy alta pero dejando el lugar suficiente como para que se vea como nace el sol sobre las aguas.

En el mismo espacio, a las espaldas de Jesús, se pueden ver como tres figuras caminan, alejándose. Se incorporan, de este modo, dos episodios de una misma temática en un mismo relieve ya que es Jesús, distinguido por su nimbo, quien encabeza ese pequeño grupo andante con el que se completa una imagen que ha sido relacionada con otras previas de Rafael y Giulio Romano ${ }^{18}$. Estamos ante un modo de hacer complejo, que suma más de un momento de una misma historia en un mismo marco, siguiendo formas ya habituales en el primer Renacimiento pero partiendo de conceptos, por las fuentes utilizadas, a relacionar ya con el Manierismo.

En parecidos términos cabe valorar la Condena y martirio de Santiago, asunto inspirado en la Leyenda Dorada de Santiago de la Vorágine ${ }^{19}$ (Fig. 7). En este caso se reparte el espacio en dos: 


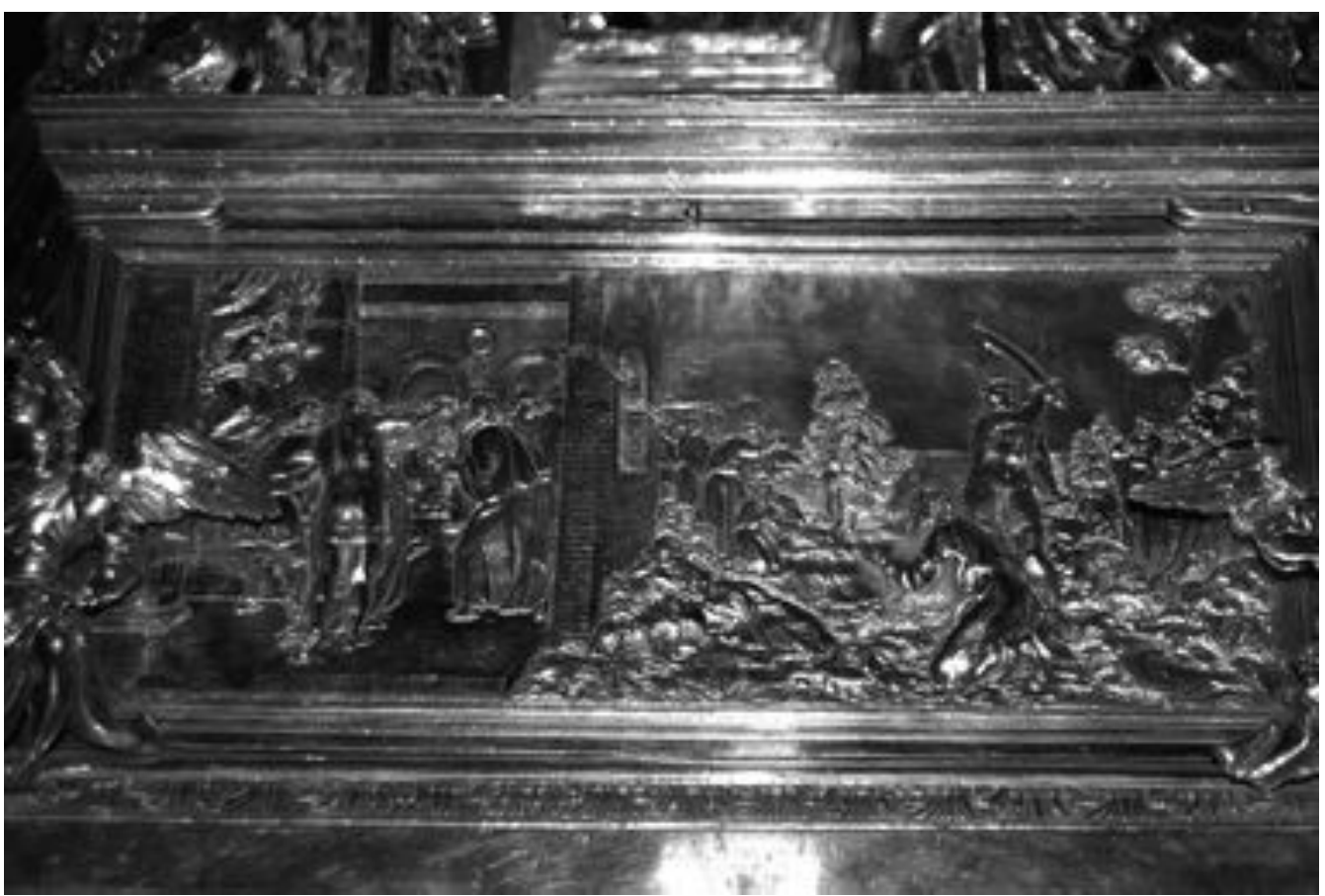

Fig. 7. Condena y martirio de Santiago

en un lado se puede ver, en un interior, el juicio, con las figuras de Santiago, Herodes Agripa, Josías y otros personajes. La otra mitad del relieve, concebida en un paisaje, lo centra, en primer plano, la decapitación. Ya, en una disposición más lejana, puede verse, a la derecha, como Santiago bautiza a Josías, antes del martirio de ambos; y a la izquierda se encuentran, dialogando, Santiago y el mago Hermógenes.

La supuesta profundidad del paisaje se insinúa, en este caso, añadiendo a la propia de la construcción aquí representada, la de una serie de elementos de la naturaleza, que agudizan tal sensación. Se ha insistido, en este caso, en que, para esta escena, se han utilizado modelos rafaelescos ${ }^{20}$.

También en la Traslación del cuerpo de Santiago la representación de la naturaleza ampara momentos diferentes de una misma historia, siguiendo, entre otros relatos, lo que dice Santiago de la Vorágine (Fig. 8). Se representa, de este modo, el robo del cuerpo, en la parte izquierda y en un primer plano; esto sucede dejando atrás unas arquitecturas que sugieren ese lugar de Jafá en donde se inicia el camino, con la barca a la orilla del mar. A la izquierda vemos el mar abierto. La presencia de un árbol, a la orilla en primer plano, contribuye a generar la idea de espacio para mostrarnos, en medio de las aguas ya, la barca navegando. Una amplia luminosidad que desciende de los cielos, sobre dicha barca, testimonia, por lo demás, un tiempo diferente para cada parte de lo mostrado. El traslado se inicia en la noche; ahora, en plena navegación, el día parece estar en su plenitud. En este caso se ha relacionado con un grabado a relacionar con Francesco Primaticcio ${ }^{21}$.

En el relieve que nos muestra los milagros de Duio y Negreira se siguen algunos de los recursos ya vistos en la escena de la Condena y martirio de Santiago ya que, también aquí, se reparte el espacio entre el de una edificación, de la que vemos su interior, en donde se puede ver al ángel liberando a los dos discípulos en la prisión de Duio, y un espacio abierto, en el que se continúa el relato. Se trata de un asunto que narra, igualmente, la Leyenda Dorada (Fig. 10). 


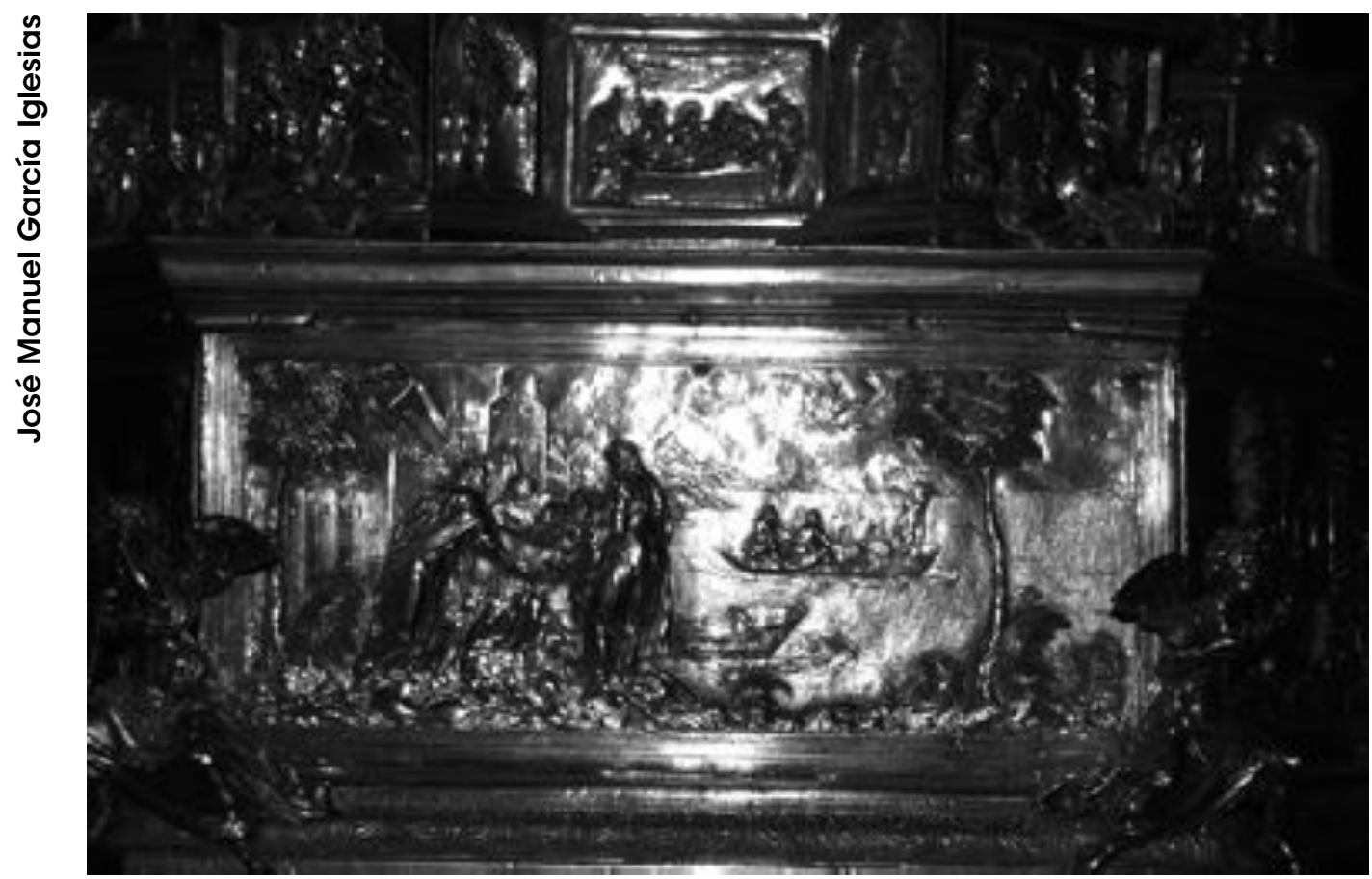

Fig. 8. Traslación del cuerpo de Santiago

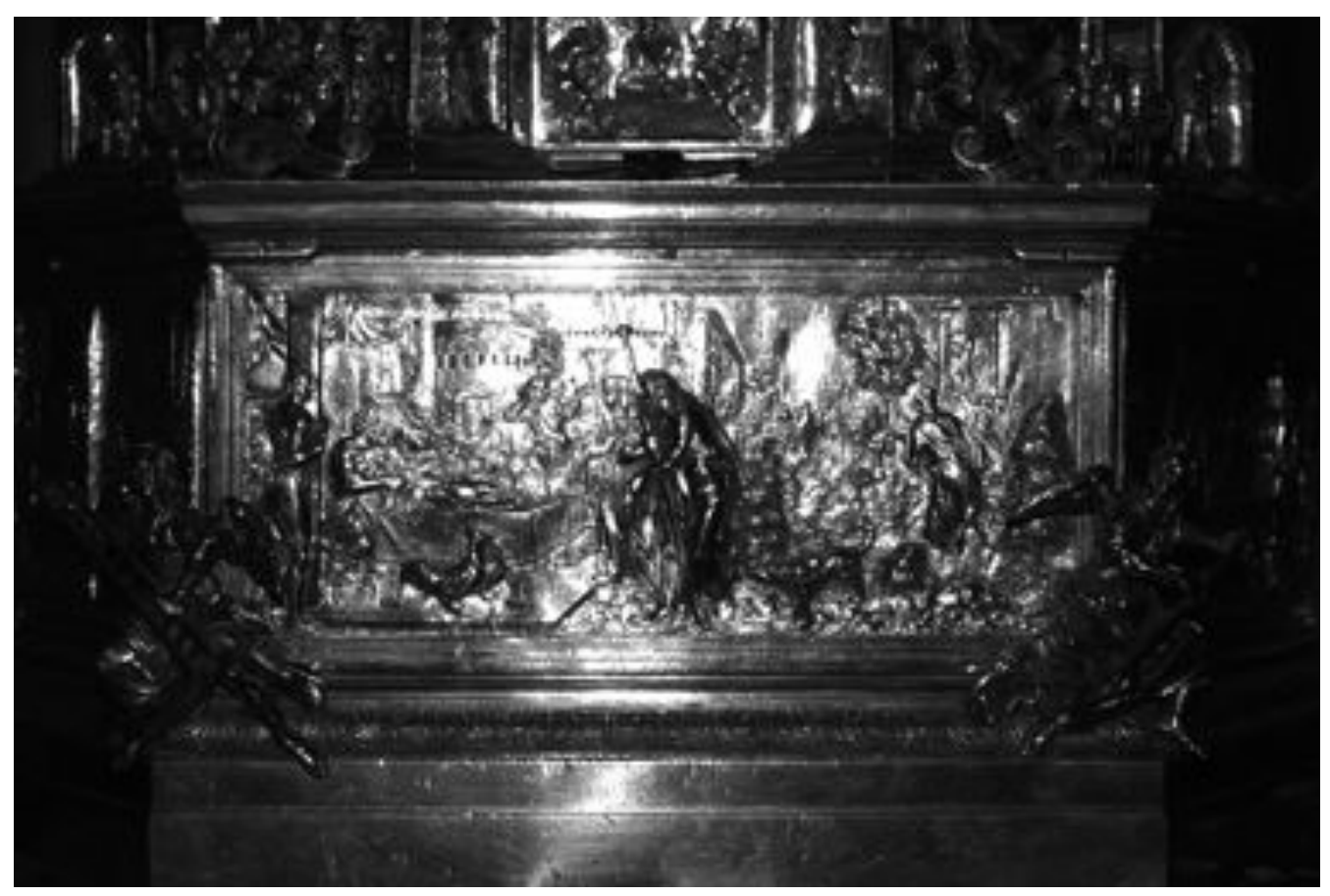

Fig. 9. "Del peregrino colgado..." 


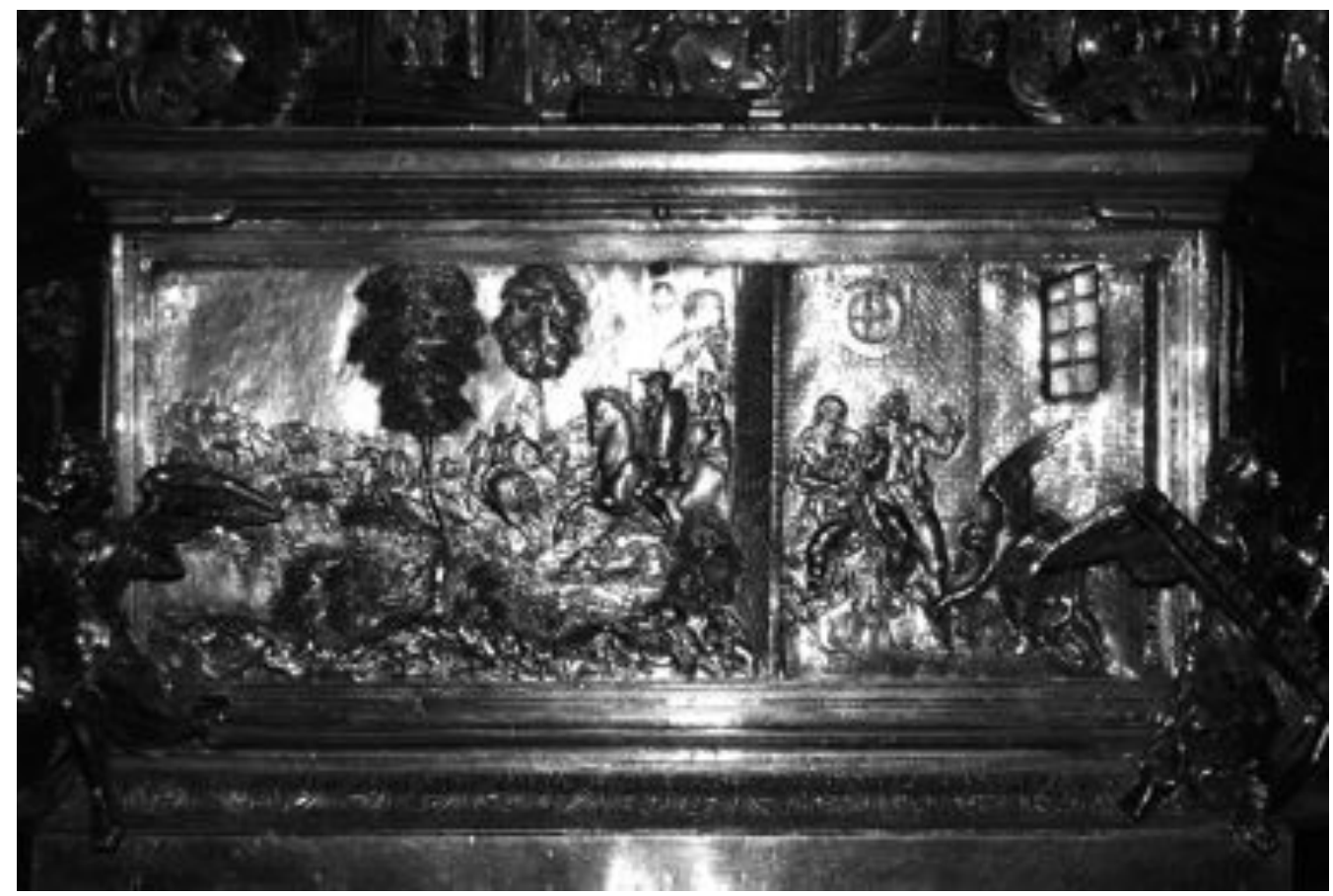

Fig. 10. Milagros de Duio y Negreira

Lo que aquí se procura es precisar un territorio concreto gallego, aludiéndose al de Duio -en la parte central, y más próxima-y a Negreira, hacia la izquierda, en la parte más alejada, contemplándose, en la distancia, la huida de los discípulos, tras lo que, milagrosamente, el puente que salva el río ha quedado destrozado 22 . Un par de árboles generan, hacia la mitad de la representación, una determinada sensación espacial; entre ellos, unos caballeros, al galope, corren, infructuosamente, tras ellos.

El Códice Calixtino, con el título Del peregrino colgado a quien el santo Apóstol salvó de la muerte, aunque estuvo pendiente en el patíbulo treinta y seis días ${ }^{23}$ denomina a un milagro al que, también, se refiere La Leyenda Dorada24 (Fig. 9). El relieve se hace eco de la versión que contextualiza la acción en Santo Domingo de la Calzada, incorporando al relato el prodigio del canto de un gallo y una gallina, previamente asados, lo que se desarrolla en una de las dos partes en que cabe, también aquí, desglosar la escena; sucede ante un conjunto arquitectóni- co que supone, por lo demás, la generación de un sentido de profundidad y que simula la parte exterior de una ciudad de la que vemos una de sus puertas por las que sale una comitiva que se encamina hacia el lugar en que se encuentra, en la lejanía, el joven ahorcado. Unos árboles, a diferentes niveles de profundidad contribuyen a generar esa misma idea de profundidad con la que cabe relacionar el diferente tamaño de los personajes que forman parte de una escena cuya composición se ha relacionado con fórmulas ensayadas, primero, por Alberto Durero y, posteriormente, por Andrea del Sarto ${ }^{25}$.

\section{El sagrario (ca. 1573)}

Está ubicado en el altar mayor, bajo la custodia, desde $1573^{26}$ (Fig. 11). Tres temas de los que forman parte de la base de la custodia se utilizan para acompañar a la puerta del sagrario ${ }^{27}$, en los otros lados de la forma hexagonal28: La Elección de Santiago y los Milagros de Duio y Negreira se repiten a cada uno de los dos lados de la puerta en tanto que en la parte posterior, lo que se nos 


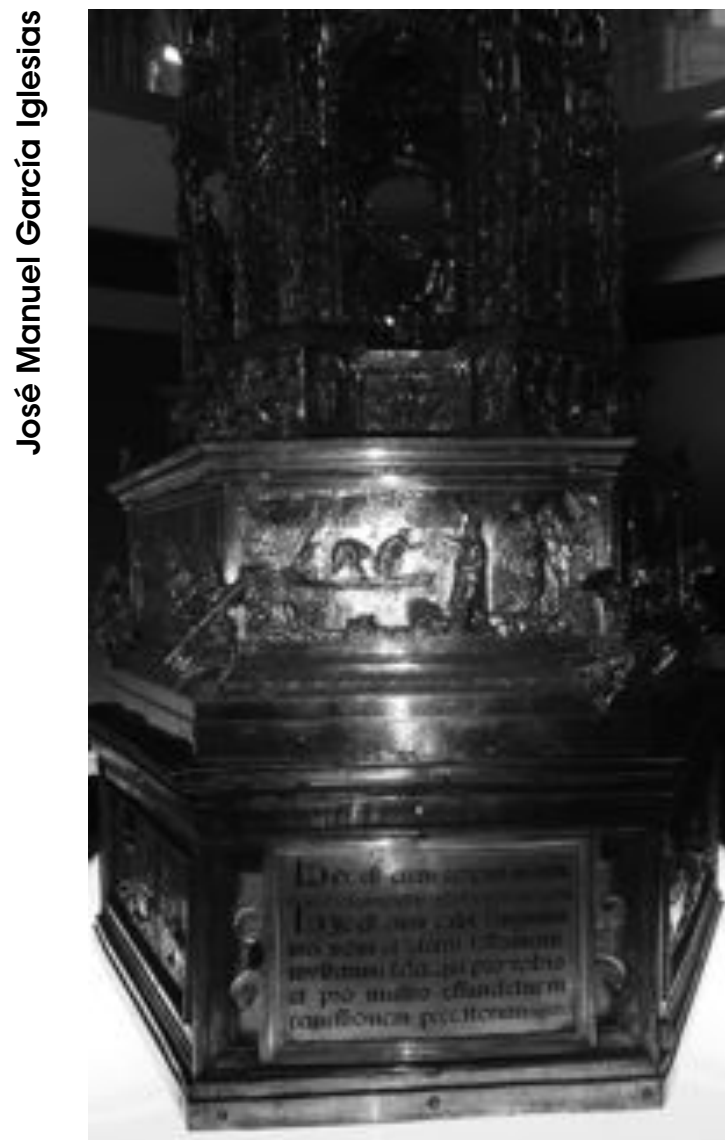

Fig. 11. Antiguo sagrario del altar mayor de la Catedral de Santiago

muestra es la Traslación ${ }^{29}$. Se trata de escenas que han sido consideradas como realizadas por "...el mismo Arfe... con anterioridad a la custodia y fue como un boceto de las escenas del basamento, o bien, un diseño hecho por Celma para las historias de los púlpitos" ${ }^{30}$.

\section{El púlpito y el corredor del Evangelio (1564-1583)}

Tal como se ha repetido usualmente los cinco relieves del púlpito y el corredor del lado del Evangelio parten de cinco de los seis temas que presentaba ya la base de la custodia. En el púlpito se representa, en dos relieves, la Traslación, los milagros de Duio y Negreira, el milagro de Santo Domingo de la Calzada y la Elección de

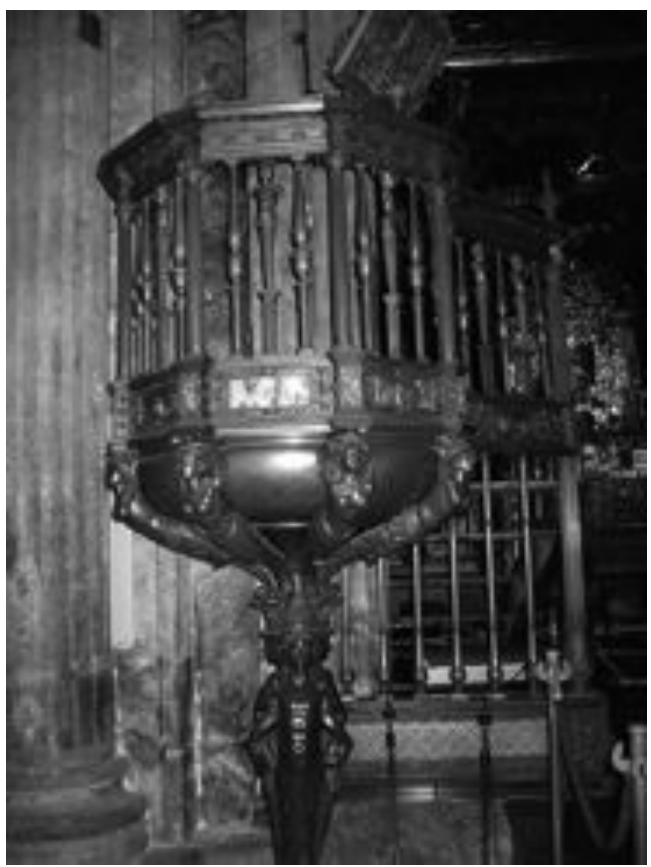

Fig. 12. Púlpito y corredor del Evangelio de la Catedral de Santiago de Compostela

Santiago. En tanto el corredor es el lugar en el que se ubica la escena de la Condena y el martirio de Santiago (Fig. 12). Así pues, con la salvedad de la Ascensión, que no se muestra en este caso, se repiten las demás escenas duplicándose, aquí, el uso de un mismo asunto: el de la Traslación. No se trata, sin embargo, exactamente de una duplicación ya que se añade, en una de tales escenas, el tema de una ciudad en la lejanía, a la que se orienta la barca, a entender bien como Padrón o bien como la inmediata Iria Flavia (Fig. 13).

\section{El púlpito y el corredor de la Epístola (1584-1586)}

Los temas mostrados en el púlpito son el Tributo de las Cien Doncellas, Las Cortes de León, El sueño de Ramiro, la Batalla de Clavijo, la Defensa de Santiago y en el corredor se representa como Alfonso II el Casto reconoce la tumba. Se aborda, en este caso, el tema del paisaje en el tributo de las cien doncellas, el sueño de Ramiro, la Batalla de Clavijo y la Defensa de Santiago (Fig. 14). 


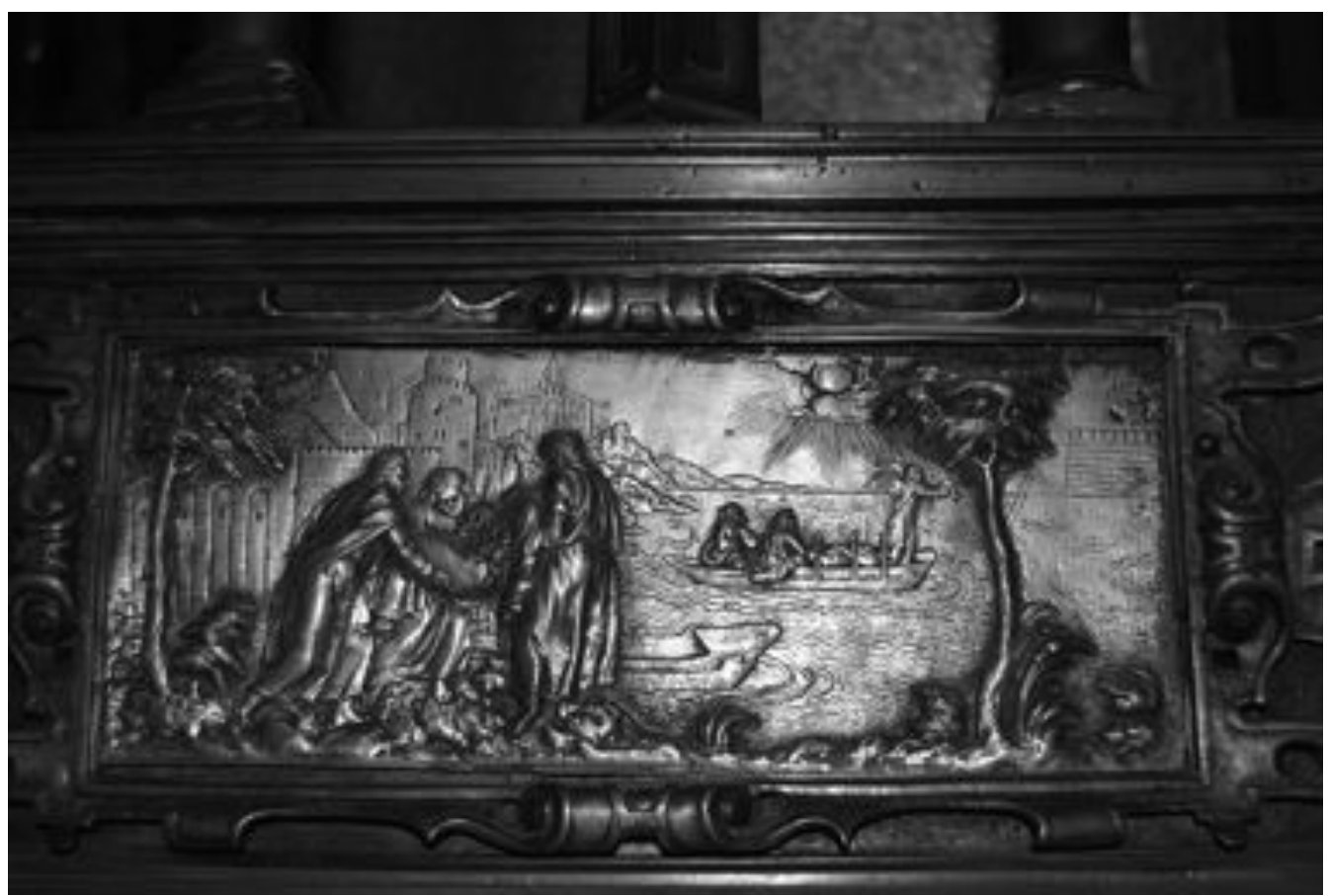

Fig. 13. El cuerpo de Santiago en las cercanías de Padrón

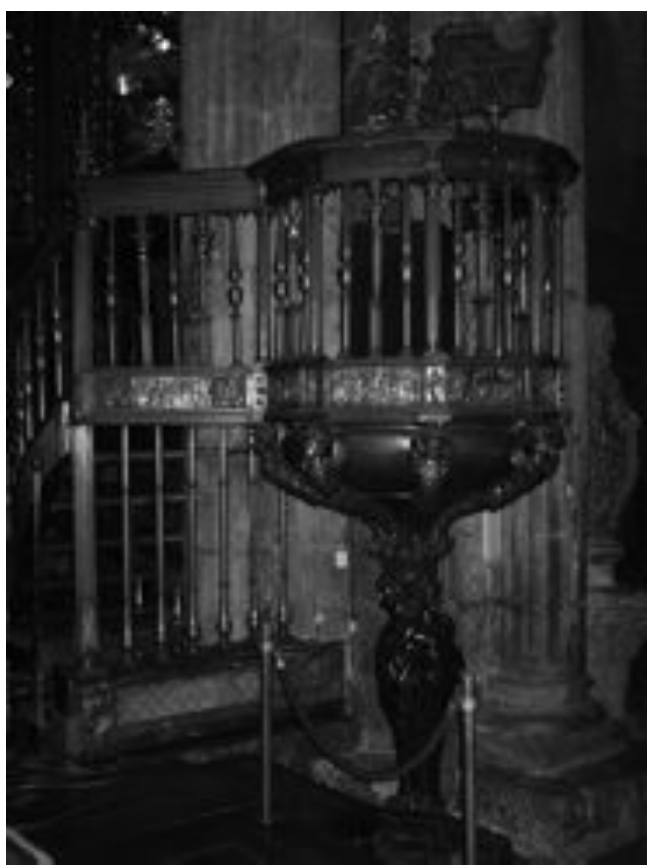

Fig. 14. Púlpito y corredor de la Epístola de la Catedral de Santiago de Compostela
El tema del Tributo ${ }^{31}$ tiene como fondo un montañoso paisaje, quizás alusiva a la tierra asturiana (Fig. 15). Prima, en este caso, la unidad en el tratamiento del relato; se trata aquí de mostrar la marcha; están ya en camino. Un grupo de cristianos varones parecen provenir de ese lejano territorio montañoso, en tanto las doncellas objeto del tributo, en el supuesto lugar más próximo, se encaminan hacia el fondo de tal forma que, en este caso, el primer plano viene a ser una especie de curva en el camino.

La Primera Crónica General de España (1289) recoge el tema de la Aparición de Santiago al rey don Ramiro, vinculándolo, particularmente, con Ramiro I $^{32}$ (Fig. 16). Con razón se reconoce, habitualmente, este episodio como "La batalla de Albelda" ya que esa contienda es previa a otra batalla, ésta victoriosa, la de Clavijo. Un amplio paisaje lo enlaza todo. Si en el primer plano se nos muestra como la tropa islámica persigue a la cristiana, en un altozano, más lejano, vemos a donde se retiran los transitoriamente vencidos; ese es el sitio en el que se nos muestra el tema principal del relieve; allí puede verse al rey Ra- 


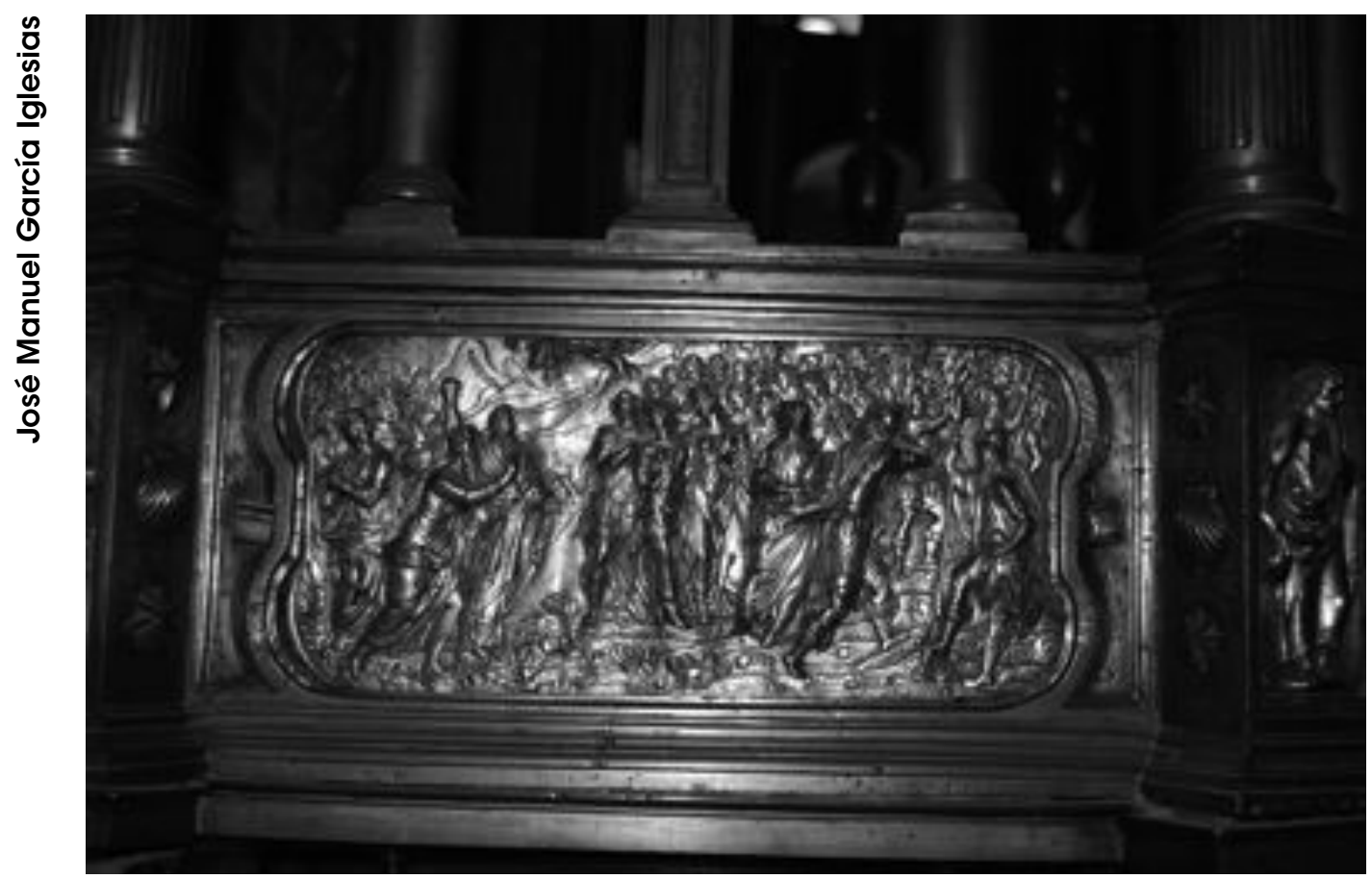

Fig. 15. El Tributo de las Cien Doncellas

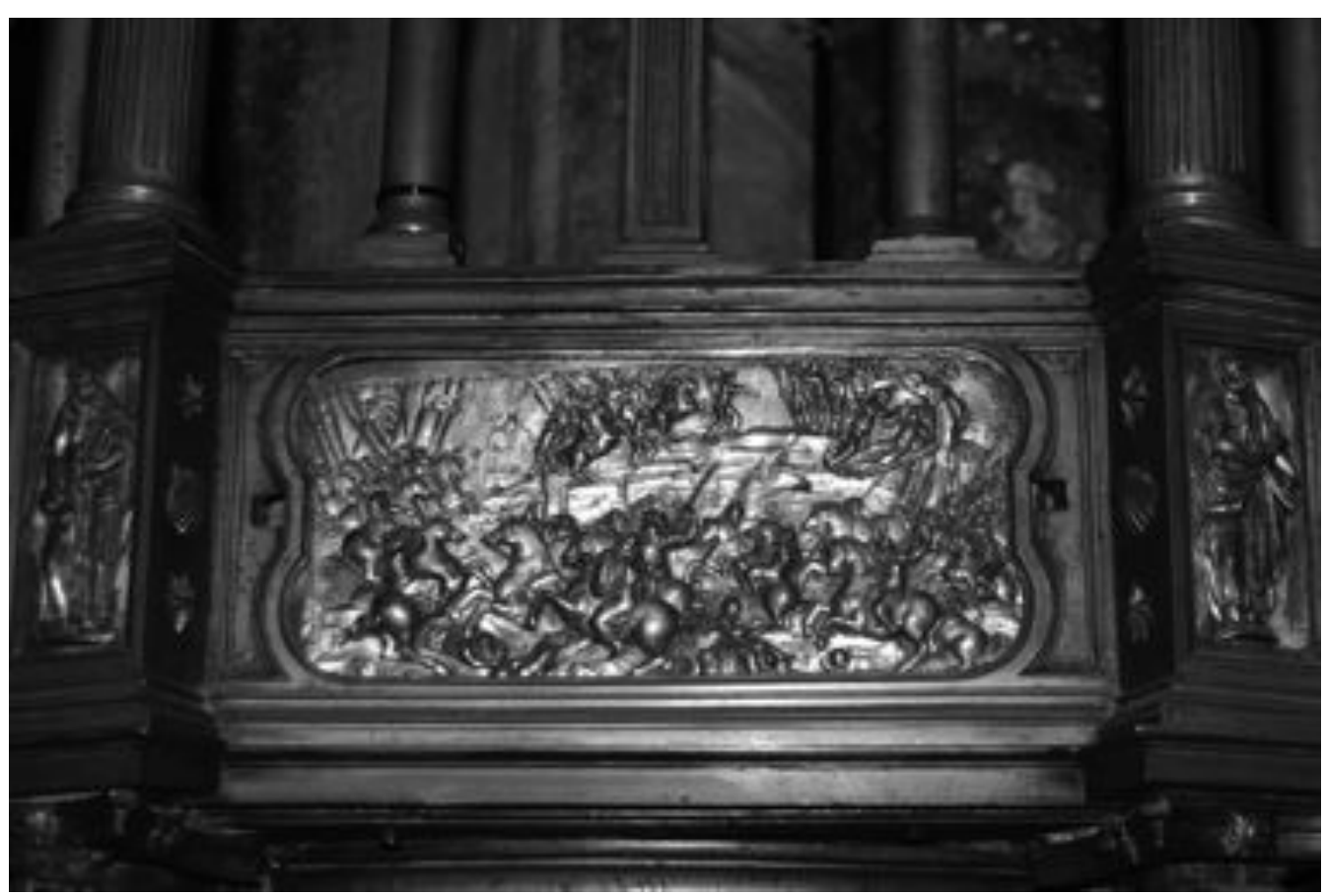

Fig. 16. La aparición al rey don Ramiro

QUINTANA Nº11 2012. ISSN 1579-7414. pp. 61-78 


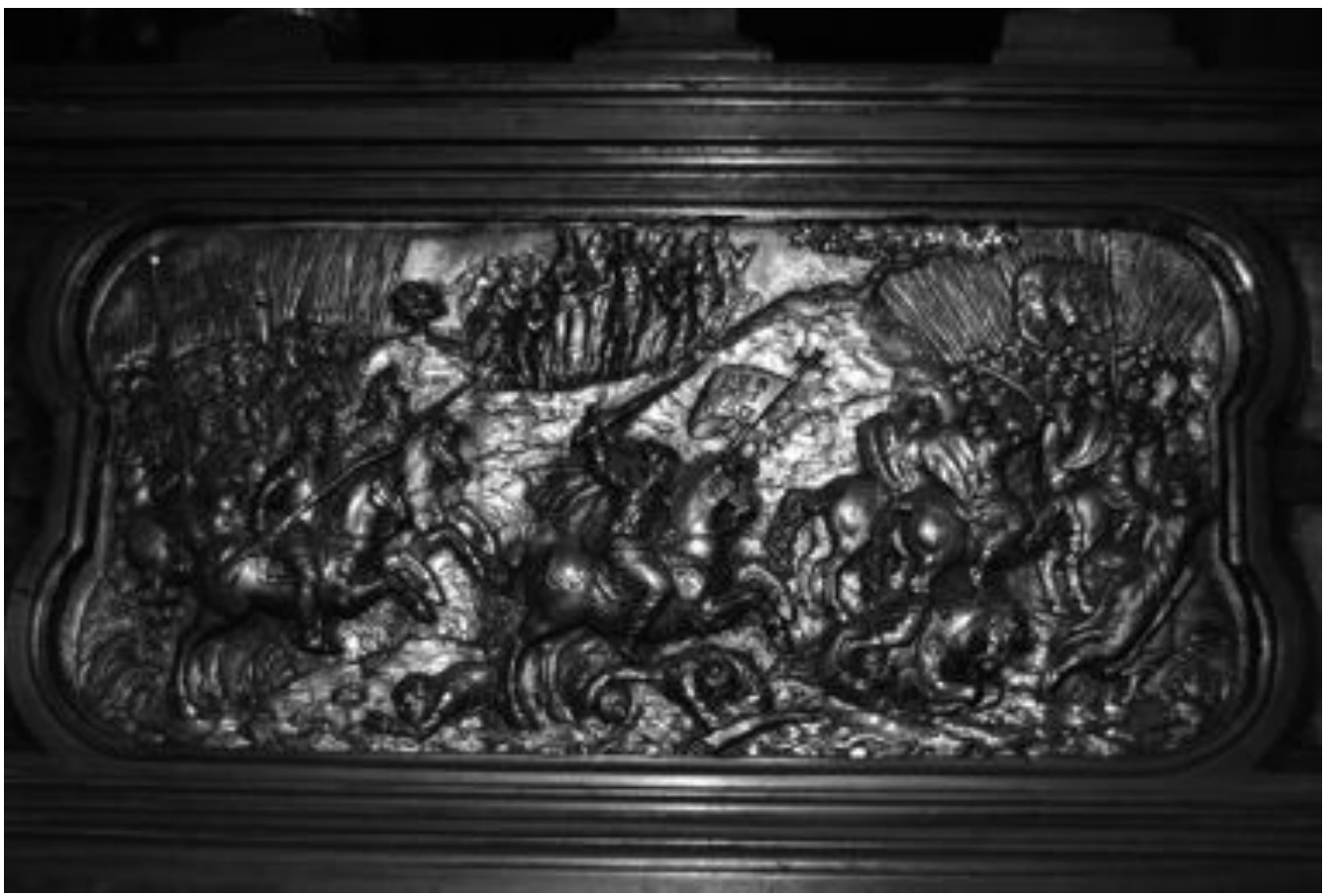

Fig. 17. La Batalla de Clavijo

miro I, acostado con su armadura y la espada próxima a su mano, y también, en pie, el Apóstol Santiago dirigiéndose al monarca. Ambas figuras se encuentran dentro de un espacio cuya forma se aproxima a la de una vieira ${ }^{33}$. Todavía, en la representación paisajística, puede verse algo que se dispone más lejos; se trata de mostrarnos, en lo alto de una montaña, una serie de arquitecturas que nos remiten al lugar de Clavijo.

También la escena de la Batalla de Clavijo cabe relacionarla con la Primera Crónica General de España (1289) ${ }^{34}$, con una de las miniaturas de la Real Ejecutoria de $1576^{35}$ y con otros mode$\operatorname{los}^{36}$ (Fig. 17). Se sigue una forma de representación muy próxima a la vista en la escena anterior con un tratamiento del paisaje muy semejante y con modo de plantear la composición que sigue, igualmente, criterios similares con la gran diferencia de que, ahora, el curso de la victoria es en sentido contrario, con el protagonismo de un apóstol ecuestre al frente de la tropa cristiana. Una vez más se remite al segundo plano para presentar algo principal; en este caso se nos muestra, también, al rey, acompañado por re- presentantes de la iglesia y un grupo de figuras orantes antes de ir al combate.

Se cierra el ciclo del púlpito de la epístola con la escena que reseña lo que puede denominarse tanto la Defensa de Santiago como la Derrota de los normandos ${ }^{37}$, con un punto de partida en el modo de entender la composición similar al visto en la representación bélica de Clavijo ${ }^{38}$ (Fig. 18). Tanto es así que existe una buscada similitud entre el modo de representarse la batalla en ambas escenas, lo que cambia, en este caso, es el paisaje; es decir, el lugar en el que se entiende que se lleva a cabo la batalla, usualmente entendida en las proximidades del faro de Brigantium (o faro de Hércules, en A Coruña). Una vez más Celma va a utilizar el segundo plano, también en clave paisajística, para mostrarnos cual es el verdadero sentido que tiene lo que sucede ante nosotros. En donde en las escenas anteriores se encontraba mostrado el anuncio del Apóstol al Rey de una próxima victoria, en un caso, y el reconocimiento regio de la ayuda que se estaba recibiendo en el otro, lo que aquí se nos muestra es una ciudad, en la lejanía, sita entre montañas, 


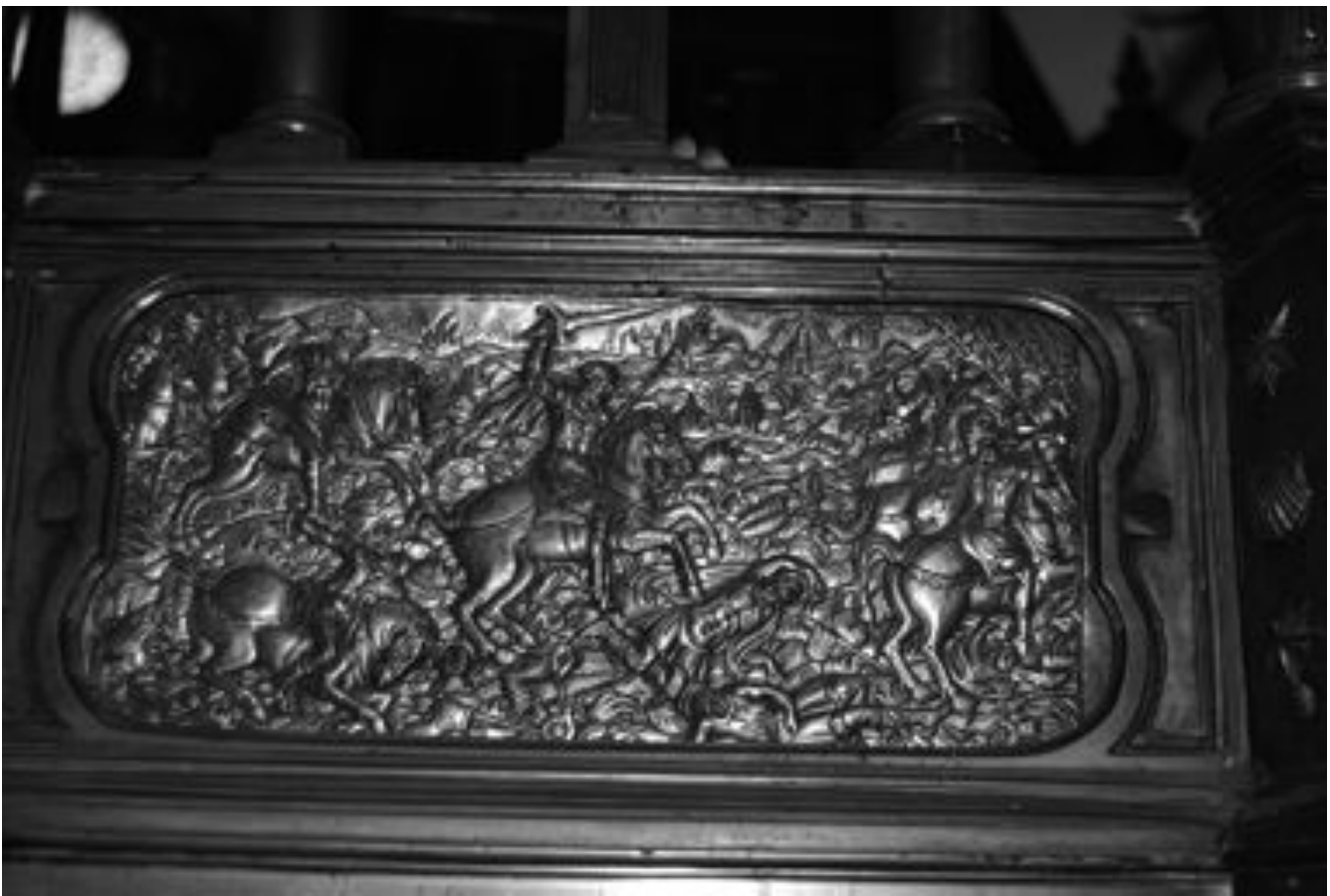

Fig. 18. La Defensa de Santiago

una de ellas con la característica forma del Pico Sacro, aludiéndosenos de tal modo a Compostela. Por eso cabe entender esta escena, siendo la batalla contra los normandos, como una auténtica defensa de la urbe jacobea, por cierto, también necesitada de ayuda en estos tiempos de Felipe $\|^{39}$, y quizás, también, Padrón como telón de fondo. Curiosamente esta escena dará lugar ya en el XVIII a otra variable, que se puede ver en la que fue campana de la torre del Reloj, en donde la interpretación paisajística es más genérica, lo que cabría reconocer como una "Defensa de Galicia." 40.

\section{7. ¿Antonio de Arfe o Juan Bautista Cel- ma?}

La valoración de los relieves del primer nivel de la custodia, de su basamento hexagonal, del sagrario, del púlpito y del corredor del lado del evangelio y del púlpito de la epístola lleva a valorar, en este caso, el reconocimiento de dos sensibilidades en el modo de entender el paisaje desde el arte.
A nuestro modo de ver cabe entender como obra de Antonio de Arfe la generalidad del trabajo realizado por 1542 . También puede relacionarse con este artífice la escena de la Transfiguración del basamento, realizado por 1573. El hecho de que los criterios estéticos y estilísticos desde los que se concibe y de que sea la única escena de esta parte de la obra que no se tiene en cuenta en la obra del púlpito y corredor del lado del evangelio nos llevan a proponer esta posibilidad.

Entendemos que las otras cinco escenas del basamento son "pintadas" y, posiblemente, abocetadas por Juan Bautista Celma. Que se nos presente como "pintor", firmando el conjunto de la obra, a la hora de repetir los contenidos de las mismas, prácticamente de una forma literal, en el púlpito y corredor del lado de la epístola se entiende mejor reconociéndole a él -pintorcomo autor que a Antonio de Arfe -artífice de una obra propuesta- en el trabajo previo de la custodia y sagrario. $Y$ es que no solo el planteamiento de los púlpitos es anterior al del basa- 
mento de la custodia sino que, también, resulta muy difícil adjudicar como obra enteramente propia de los relieves en cuestión a un Antonio de Arfe que, en ese momento, está viviendo los momentos finales de la vida y en cuya obra anterior no cabe reconocer ninguna otra que guarde similitud con este trabajo hecho para la catedral compostelana. La evidencia de que son dos estilos distintos los que pueden verse en la custodia, entendiendo como de una mano diferente el basamento, es una cuestión que apunta Rosende ${ }^{41}$, lo que ha llevado a diferentes autores a proponer una proximidad estilística ${ }^{42}$ e, incluso, una presencia de Juan de Arfe en este nuevo trabajo ${ }^{43}$, cuestión que, sin embargo, fue puesta en duda por otros, señalándose diferencia de criterios con respecto a otros trabajos de Juan como la custodia de la catedral de Ávila (1564-1571)44, algo que también puede observarse si analizamos una obra posterior suya en la que existen importantes relieves: la custodia de la catedral de Valladolid (1587-1590)45. Es más, en el probable hecho de que la escena de la Transfiguración sea obra de Arfe puede entenderse como una explicación añadida que justifique su no inclusión en la obra de los púlpitos para la que Celma quiere su autoría total.

¿Cómo pudieron ser cinco los posibles relieves proyectados por Celma para la custodia y no seis, teniendo en cuenta su formato hexagonal? Es posible que, en un primer momento se pensase en un basamento no integrado en el conjunto de la custodia que tuviese la condición de sagrario. En ese caso ese sexto lado sería el principal y el que iba a ser ocupado por la puerta del sagrario en cuestión. Al pensarse en generar un basamento independiente del sagrario se hizo necesaria una sexta escena, la concebida a nuestro criterio por Arfe.

Estamos, en todo caso, ante un tratamiento de lo paisajístico planteado en un momento en que el desarrollo del mismo no era habitual en Galicia y, en el caso de plantearse, dominaba en el mismo su carácter ideal, simbólico o fantásti$\mathrm{CO}^{46}$. Si los paisajes que aquí se relacionan con Antonio de Arfe acomodan su forma a un Re- nacimiento incipiente, lo que vinculamos a Juan Bautista Celma parten de un modo de interpretar lo renacentista mucho más complejo, con algunos modos de hacer que se rastrean en el primer Renacimiento -sumar más de un episodio en una misma escena-, con un tratamiento del espacio que asume muchas veces la contemplación de muy amplios ámbitos, siguiendo un tipo de discurso propio de los pintores del norte - "los "oltramontani" -47 , con una valoración de temas principales llevados a un segundo plano, atendiendo a un modo de hacer propio del manierismo, como también manierista resulta el modo de utilizar la parte más próxima de la representación con asuntos que tienen, en más de una ocasión un cierto tono anecdótico. Los animales que vemos delante tanto en la escena de la Elección como en el milagro de Santo Domingo de la Calzada significan, por otra parte, la inclusión de un cierto tono anecdótico que no encaja muy bien con el espíritu posterior al Concilio de Trento, atendiendo a autores como Conradus Brunus (1548) y Carlos Borromeo (1566/1582) ${ }^{48}$.

El paisaje, en una buena parte de la reseñada aportación de Juan Bautista Celma aporta una cierta carga dramática, algo en lo que converge, también con otros pintores del norte y de otras escuelas; es el caso de la veneciana ${ }^{49}$. Se ha puesto de manifiesto, últimamente, una cierta relación entre lo que se denomina rigor tridentino y la ausencia de paisaje en el arte ${ }^{50}$; no sucede así en este caso ya que estamos, en escenas como las reseñadas, ante auténticos paisajes porque, en más de un caso, tienen una cierta lectura independiente de la temática que ambientan llegando a dar notas puntuales significadoras de lugares concretos ${ }^{51}$.

Hay una cuestión más a la hora de argumentar una cierta unidad de estilo entre cinco de los relieves del basamento y los que pueden verse en el púlpito. Y es que el modo de interpretar el espacio guarda, en muchos casos, sintomáticas semejanzas a tener en cuenta. Así, la escena del milagro de Santo Domingo de la Calzada y la de la batalla de Clavijo, pongo por caso, se conciben partiendo de pautas similares. 


\section{NOTAS}

1 Se escribió en el marco del Grupo de Investigación "IACOBUS (GI.1907)", en los proyectos "MICINHAR2011-22899", "INXIRW 09263 $131 \mathrm{PR}^{\prime \prime}$.

2 Sobre este autor conviene consultar: SÁNCHEZ CANTÓN, F. J., LOS Arfes. Escultores de plata y oro (15011603), Madrid, 1920, pp. 33-46; FUENTES, M. I., “Dos dibujos de Antonio de Arfe", Boletín del Seminario de Estudios de Arte y Arqueología, LIII (1987), pp. 347-349; CRUZ VALDOVINOS, J. M., "Antonio de Arfe y la custodia de la catedral de Santiago", en VV. AA., Galicia no tempo 1991. Conferencias/ Otros estudios, Santiago de Compostela (Xunta de Galicia), 1992, pp. 245259; HERRÁEZ ORTEGA, M. V., "Vida y obra del platero Antonio de Arte en León", en Homenaje al profesor Hernández Perera, 1992, pp. 659-664; SANTAMARÍA, B., "Obra documentada de Antonio de Arfe para el VI Conde de Benavente. Estudio de tipos de platería civil en el siglo XVI", Anuario del Departamento de Historia y Teoría del Arte, VI (1994), pp. 197-204; HERRÁEZ ORTEGA, M. V., "Los Arfe. Teoría y Praxis, en La platería en la época de los Austrias Mayores en Castilla y León, Valladolid, 1999, pp. 91-110; HERRÁEZ ORTEGA, M. V., "La familia de los Arfe", en SANZ SERRANO, M. J. (coord.), Centenario de la muerte de Juan de Arfe (1603-2003), Sevilla, 2003, pp. 15-42; SANTOS MÁRQUEZ, A. J., "Aportaciones documentales a la biografía del platero Antonio de Arfe", De arte: revista de historia del arte, 5(2006), pp. 125-131.

${ }^{3}$ CHAMOSO LAMAS, M., "Juan Bautista Celma. Un artista del siglo $\mathrm{XVI}$ ", Cuadernos de Estudios Gallegos, XII, 37-38 ((1957), pp.179-195; GALLEGO DE MIGUEL, A., El arte del hierro en Galicia, Madrid (Consejo Superior de Investigaciones Científicas), 1963, pp. 116-160; VILA JATO, M. D., “El retablo de San Esteban de Orón (Burgos) y el estilo de Bautista Celma", Boletín de la Institución Fernán González, LVI, 189 (1977), pp. 199-210; VILA JATO, M. D., Escultura manierista, en Santiago de Compostela, 1983, pp. 23-47; GARCÍA IGLESIAS, J. M., La pintura manierista en Galicia, 1986, pp. 53-57; GALLEGO DE MIGUEL, A., "En torno a la polifacética actividad de Juan Tomás y Juan Bautista Celma", Boletín del Seminario de Estudios de Arte y Arqueología, LVI (1990), pp. 499-517; GARCíA IGLESIAS, X. M., "O Pintor de Banga e Juan Bautista Celma", en PULIDO NÓVOA, A. (dir.), Artistas galegos. Pintores. Ata o Romanticismo, A Coruña, 1999, p. 119; BASANTA CAMPOS, J. L, "La biblioteca de Juan Bautista Celma (1535?-1608?), Museo de Pontevedra, 54 (2000), p. 93-98.

${ }^{4}$ He tratado algunas cuestiones iconográficas relativas a estos púlpitos en GARCÍA IGLESIAS, J. M., Santiagos de Santiago. Dos apóstoles al final del Camino, Santiago de Compostela, 2011, pp. 40, 57-64, 146-150; GARCÍA IGLESIAS, J. M., "De la Elección al Voto en clave jacobea. Los púlpitos de la catedral compostelana", XIX Congreso Nacional de Historia del Arte CEHA: Las Artes y la Arquitectura del poder, Castellón, en prensa.

${ }^{5}$ Entre otros estudios, que valoran las custodias con su forma y función, patrocinio, desarrollo en la Contrarreforma y simbología, véanse: HEREDIA MORENO, M. C., "De arte y de devociones eucarísticas. Las custodias portátiles", en RIVAS CARMONA, J. (coord.), Estudios de Platería. San Eloy 2002, Murcia, 2002, pp. 163-181: SANZ, M. J., HERNÁNDEZ NÚÑEZ, J. C., "Las custodias-andas en el siglo XVI. Los modelos y su difusión", en RIVAS CARMONA, J. (coord.), Estudios de Platería. San Eloy 2005, Murcia, 2005, pp. 525-540; RIVAS CARMONA, J., "El patrocinio de las platerías catedralicias", en RIVAS CARMONA, J. (coord.), Estudios de Platería. San Eloy 2004, Murcia, 2004, pp. 479-498; RIVAS CARMONA, J., "El impacto de la Contrarreforma en las platerías catedralicias", en RIVAS CARMONA, J. (coord.), Estudios de Platería. San Eloy 2003, Murcia, 2003, pp. 515-536; HEREDIA MORENO, M. C., "El templo de Salomón en la platería española", en RIVAS CARMONA, J. (coord.), Estudios de Platería. San Eloy 2009, Murcia, 2009, pp. 313-334; COTS MORATÓ. F. de P., , "Las custodias valencianas: análisis de una tipología", en RIVAS CARMONA, J. (coord.), Estudios de Platería. San Eloy 2002, Murcia, 2010, pp. 195-220.

${ }^{6}$ Véanse SÁNCHEZ CANTÓN, F. J., op. cit., pp. 34-38; BRASAS EGIDO, J. C., La platería vallisoletana y su difusión, Valladolid, 1980, pp. 325-327; ROSENDE VALDÉS, A. A., "El Renaci- miento", en VV.AA., Historia del Arte Gallego, Madrid, 1982, p. 265; SEIXAS SEOANE, M. A., A Custodia da Catedral de Santiago (Tesis de licenciatura inédita, Facultade de Xeografía e Historia, Universidade de Santiago de Compostela), Santiago de Compostela, 1986; BARRAL, A. B., "Custodia procesional", en (catálogo de exposición) Galicia no Tempo, Santiago de Compostela, 1990, pp. 346-347; CRUZ VALDOVINOS, J. M., "Antonio de Arfe y la custodia de la catedral de Santiago", en VV.AA., Galicia no tempo 1991. Conferencias/ Otros estudios, Santiago de Compostela, 1992, pp. 245-259; FERNÁNDEZ, A., MUNOA, R., RABASCO, J., Marcas de la plata española y virreinal, Madrid, 1992, pp. 1667-167; LLAMAZARES RODRÍGUEZ, F., "Orfebrería eucarística: la custodia procesional en España", en FERNÁNDEZ JUÁREZ, G., MARTíNEZ GIL, F. (coordinadores), La fiesta del Corpus Christi, Cuenca, 2002, p. 134; RIVAS CARMONA, J., "Los otros usos de las custodias procesionales", en RIVAS CARMONA, J. (coord.), Estudios de Platería. San Eloy 2007, Murcia, 2007, pp. 508-511; MONTERROSO MONTERO, J. J., op. cit., 1998, pp. 179-222; VARAS RIVERO, M., "La custodia de la Catedral de Santiago de Compostela de Antonio de Arfe: la consolidación de un modelo renacentista", en RIVAS CARMONA, J. (coord.), Estudios de platería. San Eloy 2009, Murcia, 2009, pp. 747-763.

7 Sabemos que en 1551 se dispone: "Que se ponga el Smo. Sacramento en el Altar Mayor en la Custodia grande de plata dorada que esta en el tesoro..."; estaba, pues, entonces, en otro lugar. En tanto, en el Inventario de 1569, se dice: ... en el mesmo altar hesta una custodia de plata dorada la qual tiene quatro capillas... esta sentada sobre una peana de Madera dorada en la qual esta el sanctisimo Sacramento".

${ }^{8}$ El Retablo del Altar no es más que como Arca, formada de buen talle en la frontera y tumbado della; es tan larga como todo el Altar... Delante esta tabla está el Santísimo Sacramento en la misma Custodia de plata dorada, en que le llevan en procesión en el dia de su Fiesta...", en Morales, A. de, Viage de Ambrosio de Morales por orden del rey $D$. Phelipe II a los reynos de Leon, y Galicia, y Principado de Asturias... dale á luz con notas, con la vida del autor y 
con su retrato,... Henrique Florez, Madrid, 1765, p. 120.

9 ...la custodia del Santísimo Sacramento que está en el altar Maior del Apostol señor Santiago....", en SEIXAS SEOANE, M. A., op. cit., 1986, p. 131.

${ }^{10}$ La fecha de 1583 puede leerse en las bases de los púlpitos. En el del Evangelio dice: IOANNES BAPTISTA CELMAIARAGONENSIS PICTOR ANNO D/1583 COMPOSTELLAE FACIEBAT. Y en el de la Epístola: IOANNES BAPTISTA ÇELMA/ ARAGONENSIS PATRIA PINI GENDI ARTIFEX SALUTIS ANNOI MDXXXIII COMPOSTELLAE FACIE/BAT. Se transcriben, con ligeras variantes, en Fernández Sánchez, J. M., Freire Barreiro, F., Santiago, Jerusalén, Roma: diario de una peregrinación a estos $y$ otros santos lugares de España, Francia, Egipto, Palestina, Siria e Italia, en el año del jubileo universal de 1875, Santiago de Compostela, 1881) p. 51; López Ferreiro, A., Historia de la Santa A. M. Iglesia de Santiago de Compostela, Santiago de Compostela, 1905, t. VIII, p. 409; GALLEGO DE MIGUEL, A., op. cit., 1963, pp. 121, 131; VILA JATO, M. D., op. cit, 1983, pp. 286-287.

11 Véase GALLEGO DE MIGUEL, A., op. cit., 1963, pp. 157-159. Transcribe los documentos recogidos con el número 43 en un tomo, titulado VARIA, del Archivo de la Catedral de Santiago de Compostela. Pueden verse aquí el peso realizado el 23 de mayo de 1583 del púlpito del Evangelio. En tanto los del corredor del lado del Evangelio y del púlpito de la Epístola se pesarán el 13 de febrero de 1584. Desde la información aportada contamos con datos sobre el grado de realización propios de esos dos momentos: se da cuenta, además, de este modo, del estado en que está realizado el conjunto de la obra en cada momento. Así, al tratar sobre el del lado de la Epístola, "... que quedan por pesar las historias q. son de cobre... por no estar fechas...". Es decir, lo que faltaba por hacer, en 1584 , se encuentran las escenas del púlpito del lado de la Epístola y, probablemente las dos que se disponen, una a cada lado, en los corredores ya que no se alude a su concreción en ninguno de los pesajes. Pues bien, desde este contexto, en 1584, el Cabildo y Celma realizan un nuevo concierto para concretar la conclusión de esta obra que aporta más información - véanse López Ferreiro, A., op. cit., 1905, VIII, Apéndice XLVIII, pp.
193-196; PÉREZ COSTANTI, P., Diccionario de artistas que florecieron en Galicia durante los siglos XVI y XVII, Santiago, 1930, pp. 131-132. Ya en 1586, se le hace un pago a Celma, desde el que se reconoce que el trabajo está prácticamente ultimado; entonces se le ordena que "... perfeccionase algunas cosillas que faltaban", en GALLEGO DE MIGUEL, A., op. cit., 1963, p. 120.

12 Es entonces cuando el Cabildo compostelano envía a Celma a Porto para "buscar el açofar necesario para los pulpitos conforme a lo que se a tratado e platicado con su Señoria IIIma... cerca dello...", en López Ferreiro, A., op. cit., 1905, VIII, p. 408.

13 GARCÍA IGLESIAS, J. M., "De la Elección al Voto en clave jacobea. Los púlpitos de la catedral compostelana", XIX Congreso Nacional de Historia del Arte CEHA: Las Artes y la Arquitectura del poder, Castellón, en prensa.

${ }^{14}$ No debe de pasar el sentido simbólico que se le suele dar a determinadas. Asi lo tiene el árbol, en general, y la palmera, en particular. Véase IMPELLUSO, L., La naturaleza y sus símbolos. Plantas, flores y animales, Barcelona, 2003, pp. 16, 25.

15 MONTERROSO MONTERO, J. J., op. cit., 1998, p. 191.

${ }^{16}$ GARCÍA IGLESIAS, J. M., op. cit., 2011, p. 34. Debe de recordarse que Antonio de Arfe, ahora en Valladolid, hizo en Santiago de Compostela la primera obra de la custodia.

17 "...noticia también recogida en el evangelio ebionita, llamado de los Doce, que trascribe Epifanio (+403)", en Díaz y díaz, M.C., De Santiago y de los Caminos de Santiago, Santiago de Compostela, 1997, p. 71.

18 MONTERROSO MONTERO, J. J., op. cit., 1998, p. 192.

19 MONTERROSO MONTERO, J. J., op. cit., 1998, p. 185.

${ }^{20}$ GALLEGO DE MIGUEL, A., op. cit., 1963, p. 124; VILA JATO, M. D., op. cit., 1983, p. 35; MONTERROSO MONTERO, J. J., op. cit., 1998, p. 196.

${ }^{21}$ MONTERROSO MONTERO, J. J., op. cit., 1998, p. 198.

22 "...al passar de una puente que estava sobre el rio Tambre (llamado de los Geografos Tamaris) rompiose, y hundiose con ellos, y allí fueron muertos y agentdos. Està esta puente assi cayda como cayò entonces, q nunca jamas se reedificò, llase la puente de Ovs..." , en CASTELLÁ FERRER, M., Historia del Apóstol de lesus Christo Sanctiago Zebedeo Patrón y Capitán General de las Españas. Madrid, 1610, pp. $130 \mathrm{r}, 130 \mathrm{v}$.

${ }^{23}$ MORALEJO, J. J., GARCíA BLANCO, M. J. (ed.), Liber Sancti lacobi. Codex Calixtinus, Santiago de Compostela, 2004, pp. 341-342.

${ }^{24}$ VORÁGINE, S. de la, La Leyenda Dorada, Madrid, 1982, t. I, pp. 401402.

25 MONTERROSO MONTERO, J. J., op. cit., 1998, pp. 203-204.

${ }^{26}$ En 1554 se toma la decisión, en Capítulo, de "... que se ponga el Smo. Sacramento en el altar mayor...". Será el 22 de mayo de 1573 cuando "... se mande dar a Antonio de Arfe veinte ducados por la peana de la custodia. En esta peana estaba la reserva del Santísimo Sacramento", en López Ferreiro, A., op. cit., 1905, t. VIII, pp. 191-192.

27 En la puerta de sagrario aparecen escritas, en caracteres góticos, las palabras que se pronuncian en la consagración del pan: Hoc est enim corpus meum;y del vino: Hic est enim calix sanguinis mei novi, \& aeterni testamenti, mysterium fidei, qui pro vobis, \& pro multis effundetur in remissionem peccatorum.

${ }^{28}$ La forma hexagonal no es ajena a determinados matices de orden simbólico; el seis es "el número de la creación, simboliza el poder divino, la majestad, la sabiduría, el amor, la piedad y la justicica", en PÉREZ-RIOJA, J. A., Diccionario e símbolos y mitos. Las ciencias y las artes en su expresión figurada, Madrid, 1971, 348.

29 Vincular la Traslación con la Custodia tiene, desde un punto de vista simbólico, sentido, como también cabe relacionar el tema con el Sagrario. Sobre la relación entre el sepulcro del Señor, a través de la denominada Anástasis de Jerusalén, con la tipología de la custodia torre véase COTS MORATÓ. F. de P., op. cit, 2010, p. 201.

30 GALLEGO DE MIGUEL, A., op. cit., 1963, p. 124.

${ }_{31}$ MILANS DE BOSCH, J. J., "Santiago caballero y el legendario tributo de las cien doncellas", en Actas del III Congreso Internacional de Asociaciones Jacobeas: actas del congreso celebrado en Oviedo del 9 al 12 de octubre de 1993, Oviedo 1994, pp. 343-350; 
ÁlvAREZ GARCíA, A., "El tributo de las cien doncellas o el precio de la paz en la Hispania de los siglos VIII-I. II Congreso Virtual de la Historia de las mujeres (del 15 al 31 de octubre de 2010, Jaén, 2010, pp. 1-8; MONTERROSO MONTERO, J. J., op. cit., 1998, pp. 205-206.

32 MENÉNDEZ PIDAL, R. (ed.), Primera Crónica General de España que mandó componer Alfonso el Sabio y se continúa bajo Sancho IV en 1289, Madrid, 1955, p. 360.

${ }^{33}$ Esta forma responde a una tradición que se recoge, al aludir a las inmediaciones de Clavijo, en donde "desde el tiēpo en q predicò en ella, se hallā estas piedras, cō las figuras de Veneras, bordones, y calabaça...", en CASTELLÁ FERRER, M., op. cit., 1610, p. $266 v^{\circ}$. Véase CASTIÑEIRAS, M., A vieira en Compostela: a insginia da peregrinación xacobea, Pontevedra, 2007, pp. 57-59.

${ }^{34}$ MENÉNDEZ PIDAL, R. (ed.), op.cit., 1955, pp. 360-361. Lo cita MONTERROSO MONTERO, J. J., op. cit., 1998, p. 209.

35 IGLESIAS ORTEGA, A., "Real Ejecutoria de Felipe II a solicitud del Arzobispo, Deán y Cabildo de la Iglesia de Santiago, contra los concejos de ciertas ciudades, villas y lugares del distrito de esta Real Audiencia de Granada sobre los votos de Santiago", (catálogo de exposición) Santiago. La Esperanza (Palacio de Gelmirez), Santiago de, Compostela, 1999, pp. 472-473. Otra de las miniaturas de esta misma Real Ejecutoria cabe ponerla en relación con la anterior escena que nos muestra el Sueño de Ramiro; véase, en este sentido, GARCÍA IGLESIAS, J. M., op. cit., en prensa.

${ }^{36}$ Se relaciona con un grabado de Pierre Baltens en MONTERROSO MONTERO, J. J., op. cit., 1998, p. 209.
${ }^{37}$ cfr. López Ferreiro, A., op. cit., 1899, t. II, p. 79; GALLEGO DE MIGUEL, A., op. cit., 1963, p. 138; VILA JATO, M. D., op. cit., 1983, pp. 142143.

38 "el origen de la escena tiene que buscarse de nuevo en el grabado de Baltens, ahora interpretada con mucha menos fortuna", en MONTERROSO MONTERO, J. J., op. cit., 1998, p. 213.

39 cfr, GONZÁLEZ LOPO, D. L., "El alto clero en tiempos de Felipe II", en EIRAS ROEL, A. (coord.), El Reino de Galicia en la Monarquía de Felipe II, Santiago de Compostela, 1998, pp. 313-344.

${ }^{40}$ Dicha campana se le contrató a Pedro de Güemes en 1710 - en COUSELO BOUZAS, J., Galicia artística en el siglo XVIII y primer tercio del XIX, Santiago de Compostela, 1933, pp. 397398- Se contratará de nuevo, al mismo autor, en 1729. Fue concluida en 1734 tal como se reseña en la propia campana: SE HIÇO ESTA OBRA SIENDO ARCOBISPO EL ILUSTRISIMO SENNOR DON JOSEPH DEL IERMO I SANTIBANES/PRESIDENTE DEL CABILDO EL DOTOR DON ANDRES DE GONDAR CHANTE I CANONIGO FABRIQUERO DON LUCAS ANTONIO DE LA TORRE/ 24 DE JULIO ANNO DE 1729/ DON PEDRO DE GUEMES ME FECIT 1734.

41 ROSENDE VALDÉS, A. A., op., cit., 1982, p. 265.

42 HERRÁEZ ORTEGA, M. V., op. cit, 1999, pp. 97; HERRÁEZ ORTEGA, M. V., op. cit., 2003, p. 39.

${ }^{43}$ LLAMAZARES RODRÍGUEZ, F., op. cit, 134, 2007.

44 CRUZ VALDOVINOS, J. M., op. cit., 1992, p. 257. Sobre los relieves con los que cabe comparar ambas custodías véase DE LA CRUZ VAQUERO, A., GONZÁLEZ GONZÁLEZ, N., La cus- todia del Corpus de Ávila, Avila, 1993, pp. 31-67.

${ }^{45}$ Véase ANDRÉS GONZÁLEZ, P., Arte, fiesta e iconografía en torno a la Eucaristía. Juan de Arfe y su obra: la custodia monumental de Valladolid, Valladolid, 2010, pp. 65-148.

${ }^{46}$ Véanse CLARK, K., El arte del paisaje, Barcelona, 1971, p. 65; LÓPEZ SILVESTRE, F., Os límites da paisaxe na Galicia dos Austrias (1517-1700), Madrid, Editorial Biblioteca Nueva, 2008, pp. 77-78; WOLF, N, Pintura paisajista, Köln, 2008, pp. 16-17; POSADA KUBISA, T., Rubens, Brueghel, Lorena. El paisaje nórdico en el Prado, Madrid, 2011, pp. 20-21.

${ }^{47}$ Véase WOLF, N, op. cit. , 2008, pp. 9, 32. Se ha hablado, con razón, de que son determinadas obras nórdicas en las que cabe visualizar lo que puede entenderse como "plenitud de la naturaleza". Véase, en este sentido, HERÓN DE VILLEFOSSE, R., "De la prehistoria a nuestros días", en ROUSELOT, J. (dir.), Las fuentes del Arte. La Naturaleza en el Arte, Barcelona, 1974, pp. 111-145.

${ }^{48}$ Véase LÓPEZ SILVESTRE, F., op. cit., 2008, pp. 126-129.

49 Véase MADERUELO, J., "Paisaje: un término artístico", MADERUELO, J., Paisaje y arte, Madrid, 2007, p. 22.

50 Veánse MADERUELO, J., El Paisaje. Génesis de un concepto, Madrid, 2006, pp . 214 y ss; LÓPEZ SILVESTRE, F., op. cit., 2008, p 214; LÓPEZ SILVESTRE, F., op. cit., 2008, pp. 114.

51 Tal como se ha explicado "... a paisaxe é certa extensión de terreo que adquire unidade e independencia grazas á mirada atenta dun home que a valora en si mesma", en LÓPEZ SILVESTRE, F., op. cit., 2008, p. 75. 